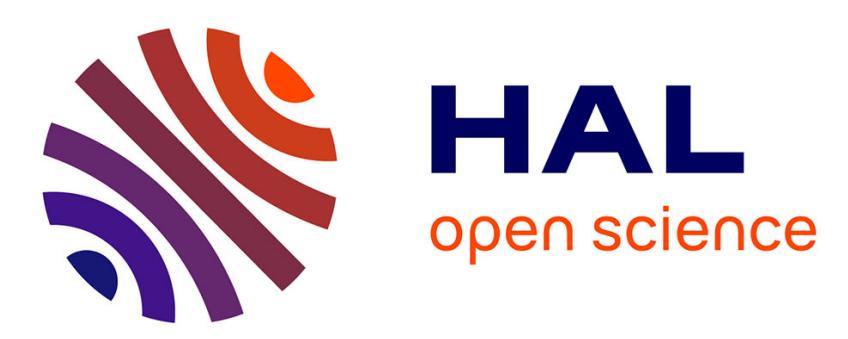

\title{
KuROS : A new airborne Ku-band Doppler radar for observation of surfaces
}

\author{
Gérard Caudal, Danièle Hauser, René Valentin, Christophe Le Gac
}

\section{To cite this version:}

Gérard Caudal, Danièle Hauser, René Valentin, Christophe Le Gac. KuROS : A new airborne Ku-band Doppler radar for observation of surfaces. Journal of Atmospheric and Oceanic Technology, 2014, 31 (10), pp.2223-2245. 10.1175/JTECH-D-14-00013.1 . hal-01055294

\section{HAL Id: hal-01055294 https://hal.science/hal-01055294}

Submitted on 12 Aug 2014

HAL is a multi-disciplinary open access archive for the deposit and dissemination of scientific research documents, whether they are published or not. The documents may come from teaching and research institutions in France or abroad, or from public or private research centers.
L'archive ouverte pluridisciplinaire HAL, est destinée au dépôt et à la diffusion de documents scientifiques de niveau recherche, publiés ou non, émanant des établissements d'enseignement et de recherche français ou étrangers, des laboratoires publics ou privés. 


\section{KuROS : A new airborne Ku-band Doppler radar for observation of surfaces}

\section{Gérard Caudal}

Université Versailles St-Quentin; UPMC Univ. Paris 06; CNRS/INSU, LATMOS-IPSL

\section{Danièle Hauser}

Université Versailles St-Quentin; UPMC Univ. Paris 06; CNRS/INSU, LATMOS-IPSL

\section{René Valentin}

Université Versailles St-Quentin; UPMC Univ. Paris 06; CNRS/INSU, LATMOS-IPSL

\section{Christophe Le Gac}

Université Versailles St-Quentin; UPMC Univ. Paris 06; CNRS/INSU, LATMOS-IPSL

Corresponding author: Gérard Caudal, LATMOS-IPSL, 11 Boulevard d'Alembert, 78280 Guyancourt, France. email : gerard.caudal@latmos.ipsl.fr

accepted in Journal of Atmospheric and Oceanic Technology (2014) 
Abstract. We present the new airborne Doppler radar KuROS (Ku-band Radar for Observation of Surfaces), which provides measurements of the normalized radar cross section $\sigma^{\circ}$ and of the Doppler velocity over the sea. The system includes two antennae rotating around a vertical axis, although only the results from the lower incidence $\left(14^{\circ}\right)$ antenna are presented here. We also give first results from observations performed during two field campaigns held in 2013 (HyMeX and PROTEVS campaigns).

Sea wave directional spectra computed by the radar from tilt modulation of $\sigma^{\circ}$ are consistent with those given by the directional wave rider moored in the Mediterranean basin, both in terms of significant wave height $\mathrm{H}_{\mathrm{s}}$ and main features of the wavenumber spectrum. As concerns the azimuthal distribution, two methods are tested to remove the $180^{\circ}$ ambiguity of the radar derived directional spectrum. The first method is based on the correlation between the modulations of $\sigma^{\circ}$ and Doppler velocity, which reflects the correlation between sea surface slope and orbital velocity. The second method does not use the Doppler velocity, but computes the cross-spectrum between the modulations of $\sigma^{\circ}$ between two power profiles separated by some time lag $\Delta \mathrm{T}$, from which the phase velocity of sea waves is deduced. Comparing the sea wave directional spectra disambiguated by both methods, with the directional spectrum given by the wave rider, we conclude that the first method (using Doppler velocity) is more efficient to remove the $180^{\circ}$ ambiguity, and should be preferred to the second method. 


\section{Introduction}

Sea state knowledge is essential both for operational needs (marine meteorology, navigation, offshore and coastal activities,...), or for research needs (better knowledge of hydrodynamics of the waves, interactions between waves and the atmospheric and oceanic boundary layers, coupling of the atmosphere and ocean systems from regional to climtologic scales, interactions between electromagnetic signals and the ocean surface). Although the performance of wave models has significantly improved in the last decades (Wise group publication, 2007), improvements are still needed, in particular for high sea-state conditions, extreme events (hurricanes, typhoons), rapidly evolving storms, and for providing accurate prediction not only in terms of wave height but also in terms of peak wavelength and direction (important for swell). Furthermore, numerical models which are presently used to predict the distribution of energy of the ocean surface waves as a function of frequency (or wave number) and direction, still suffer from various shortcomings (see Cavaleri et al, 2006) among which, uncertainties in the parameterization of source and sink terms (dissipation processes, source and sink terms related to turbulent exchanges at the interface), and errors on the prescribed initial state. In addition, due to the limitation in the model discretizations, significant errors in the directional distribution of wave energy may happen in open sea conditions and this may induce large errors on description of wave evolution when they approach the coasts.

Up to now, the only radar system implemented on spacecraft for measuring ocean wave spectra is the synthetic aperture radar (SAR). Since the pioneering work performed with the SAR mounted onboard the Seasat satellite (Gonzales et al., 1979), it appeared however that the SAR systems are expensive to develop and not trivial to use for the estimation of ocean wave directional spectra. In that context, several airborne radars operating without the constraints of SAR have been developed : the Ka-band Surface Contour radar (SCR) developed by Walsh et al. (1985), the Kuband Radar Ocean Wave Spectrometer (ROWS) developed by Jackson et al. (1985a, b), the Cband system RESSAC (Hauser et al.,1992), the C-band polarimetric system STORM (Hauser et al., 2003), and more recently the X-band coherent real aperture radar system (CORAR) developed by Plant et al. (2005). Such airborne measurements provide directional information with more details than directional buoys (Petterson et al., 2003).

The "China-France Oceanography SATellite» (CFOSAT) is a new satellite mission under preparation by the Chinese and French space agencies. It is devoted to the radar observation of directional sea wave spectra and surface winds over the ocean. It will include on the same platform a Ku-band scatterometer (SCAT) for measuring surface winds and developed by the Chinese partner, and a real aperture Ku-band radar spectrometer (SWIM) for measuring sea waves and developed in France under the support of the Centre National d'Etudes Spatiales (CNES) (Hauser et al., 2010). CFOSAT will be a polar-orbiting satellite at about $520 \mathrm{~km}$ altitude. The SWIM instrument will illuminate the surface sequentially with 6 incidence angles: $0^{\circ}, 2^{\circ}, 4^{\circ}$, $6^{\circ}, 8^{\circ}$ and $10^{\circ}$ with an antenna aperture of approximately $2^{\circ}$. To avoid limitations encountered by the SAR systems, the SWIM instrument will use a real aperture observation technique. But, in order to acquire data in all azimuth orientations, the antenna will be rotating, at a speed rate of 5.6 $\mathrm{rpm}$. The following geophysical parameters will be provided from the SWIM observations: normalized radar cross-section profiles from $0^{\circ}$ to $10^{\circ}$ incidence (combining all beams), significant wave height and wind speed from the nadir beam, similar to conventional radar altimeter, directional ocean wave spectra from the combination of the $6,8,10^{\circ}$ beams. Details may be found in (Hauser et al., 2010). 
In the context of the preparation of the CFOSAT space mission, we developed a new airborne radar, called KuROS (Ku-band Radar for Observation of Surfaces). The primary aim of KuROS is to optimise the choices made for the implementation of the CFOSAT satellite, and to serve as a tool for the geophysical validation of the CFOSAT sea wave measurements once launched. Another important objective of the KuROS radar is to explore the characteristics of the kinematics of the sea surface. For this purpose, in addition to measuring the normalized radar cross section $\sigma^{\circ}$, KuROS has the ability to measure the Doppler velocity of the radar echo, by means of the pulse pair technique as described in section 2. Such a Doppler measurement capability was already included in the X-band airborne coherent radar CORAR developed by Plant et al. (2005), who were able to deduce directional wave spectra from images of surface velocity. However those were obtained only in the side looking mode. Here we use both $\sigma^{\circ}$ and Doppler signals simultaneously in the rotating mode at low incidence (around $14^{\circ}$ ), and we will show that the Doppler information can be used efficiently to remove the $180^{\circ}$ ambiguity from the calibrated directional wave spectrum retrieved from the $\sigma^{\circ}$ tilt modulation.

In order to address the question of measuring both wind and waves, the KuROS radar system includes two antennas, one probing a range of incidence angles around $14^{\circ}$ to measure waves (hereafter called the low incidence antenna or LI antenna), and another antenna probing incidence angles around $40^{\circ}$ to measure wind (hereafter called the medium incidence antenna or MI antenna). Both antennas have been tested in anechoic chamber to determine their radiation patterns. However, when integrated within the body of the aircraft, it turned out that the antenna radiation pattern of the MI antenna obtained from calibration flights over corner reflectors (see section 4 below) did not reproduce the shape of the main lobe pattern expected from anechoic chamber measurements. This is attributed to the presence of a metal collar used to adjust the antenna system within the body of the plane, as will be discussed in section 2 . For this reason, the results presented here will be focused on the observations performed with the LI antenna. The field campaigns in which KuROS has been involved will be described in section 3 . The results of in-flight calibration of the radar will be briefly reported in section 4 , and first scientific results obtained from the analysis of radar cross section and Doppler velocity will be given in section 5 . In particular, two new methods to remove the $180^{\circ}$ ambiguity of the measurements of directional sea wave spectrum will be presented and compared.

\section{Description of the instrument}

\subsection{General characteristics}

The main characteristics of the radar system are given in Table 1. The relatively large antenna beamwidth is required to estimate ocean wave spectra from a real-aperture radar at smallincidence (see Hauser and al., 1992 or Jackson and al., 1985a). In addition, a Doppler measurement capability has been designed for KuROS. The whole system is mounted in an ATR42 aircraft, operated by the SAFIRE unit ("Service des Avions Français Instrumentés pour la Recherche en Environnement"), and the conditions of use of KuROS are specified to allow measurements from flights from about $500 \mathrm{~m}$ to about $3000 \mathrm{~m}$ above the surface.

The block diagram of the instrument is shown in Figure 1. The overall system is composed of the Antenna and Radome Unit (ARU), a Power Supply Unit (PSU), a Radio Frequency Unit (RFU), a Digital Processing Unit (DPU), a Human Interface Machine (HIM), and the whole system is controlled by a Management and Control unit (MCU). Both functions of DPU and MCU are 
entirely performed by an FPGA (Field-Programmable Gate Array) device. A more detailed description of ARU, RFU and DPU will be briefly given below.

\subsection{Antenna and radome unit}

Because of the large range of incidences to be covered, and in order to keep a cost-effective system, two antennae are necessary. We chose a system of two printed antenna arrays, the low incidence antenna (called LI antenna) pointed to $14^{\circ}$ incidence with respect to nadir and the medium incidence antenna (called MI antenna), pointed to $40^{\circ}$ incidence with respect to nadir (see Figure 2). The LI antenna operates in the HH polarization, and we chose a dual linear polarization capability $(\mathrm{HH} / \mathrm{VV})$ for the MI antenna to offer comparisons with the CFOSATSCAT measurements. This set of two antennae is mounted inside the airplane. The antenna beam points through a $40 \mathrm{~mm}$ thickness quartz window, which serves as interface between the outside and inside of the airplane at its lower part, allowing the whole radar system, including the antennae, to be under cabin pressure. Both antennae are used here through their real-aperture, without any synthetic aperture processing. The antenna system can be controlled either to rotate over $360^{\circ}$ around the vertical axis at a chosen rotation velocity, or to stop at a fixed azimuth angle. The rotation velocity and the flight altitude are determined in order to have an overlap of the ground footprints and to measure a wave spectrum of a few hundred meter wavelength. An example of the antenna footprint is shown in Figure 3. For the sake of lisibility, in Figure 3 the footprint is shown every $300 \mathrm{~ms}$. However the real time integration is performed over $1 \mathrm{~ms}$, yielding a displacement of the order of $0.1 \%$ of the footprint between successive records.

\subsection{Radio-Frequency Unit}

The transmitted wave is a pulsed chirp whose bandwidth is centered around $13.5 \mathrm{GHz}$. Because of the large range of distances to be sampled (flight altitudes from $500 \mathrm{~m}$ to $3500 \mathrm{~m}$, incidences from 0 to $50^{\circ}$ ), we have defined several chronograms of transmitted pulses, adapted to the flightaltitude and the antenna. Table 2 presents these different modes, while Figure 4 illustrates the time-frequency diagrams of the transmitted pulses. The frequency range $\left[\mathrm{F}_{\mathrm{emin}}-\mathrm{F}_{\mathrm{emax}}\right]$ of the transmitted chirp has been chosen in order to achieve a high range resolution: [25MHz-125MHz] for the LI antenna and [30MHz-60MHz] for the MI antenna, corresponding to a range resolution of 1.5 and $5 \mathrm{~m}$, respectively.

Within the DPU, two chirps in phase quadrature are generated at an intermediate frequency (IF) with frequency range as given in Table 2. A Tukey window is applied on these two signals before transmission. In RFU, this complex signal is mixed by a single sideband up-converter with the $13.5 \mathrm{GHz}$ signal generated by a coherent local oscillator (LO), as seen in Figure 1. After filtering, the signal is sent to a power amplifier. A programmable attenuator in front of the power amplifier enables to transmit a power signal lower than its nominal value so as to be able to assess the CFOSAT SNR conditions (CFOSAT SNR is $\sim 6 \mathrm{~dB}$ per pulse instead of about $11 \mathrm{~dB}$ for KuROS in nominal conditions, see below). Then, the signal goes through a passive circulator. A first mechanical switch in front of the antennae enables to commute between calibration channels, and the LI or MI antenna channels, while a second switch on the MI antenna channel commutes between the $\mathrm{H}$ and $\mathrm{V}$ polarizations (see Figure 1).

At the reception, the radar echo is multiplied by a chirp replica, whose highest frequency $\mathrm{F}_{\text {repmax }}$ cannot however exceed 180MHz due to the limitation of the FPGA (Virtex5 XC5VSX95T). We require that the beat signal between echo and replica is integrated over the whole pulse duration 
$\mathrm{T}_{\mathrm{P}}$, and as a consequence the beat signal is analysed only over the "analysis band" $\mathrm{B}_{\mathrm{A}}=\mathrm{F}_{\text {repmax }}$ $F_{\text {emax }}$. The range of distances sampled is $\mathrm{D}=\mathrm{c}\left(\mathrm{T}_{\text {rep }}-\mathrm{T}_{\mathrm{P}}\right) / 2$, where $\mathrm{c}$ is the velocity of light and $\mathrm{T}_{\mathrm{P}}$ and $\mathrm{T}_{\text {rep }}$ are the pulse and replica durations, respectively, whose values are chosen for each antenna depending upon altitude, as given in Table 2. All these modes are pre-loaded in the management and control unit, and chosen by the operator during flights.

After going through the two switches and the circulator, the received chirps are sent to a low noise amplifier. They are then filtered to limit the noise band and conserve only the upper band with the received signals. The microwave signal is down converted with the same coherent local oscillator as used in the transmitter part. The signals are then amplified, filtered by an antialiasing filter and sent to the analogic digital converter (ADC) of the DPU.

In nominal mode, the wave form is transmitted alternately at low rate ( 30 seconds) to the LI and MI antennae (for MI antenna, a switch commutes every $100 \mathrm{~ms}$ between the $\mathrm{H}$ and $\mathrm{V}$ polarizations). It is also possible to use continuously a single antenna (LI or MI antenna) or to use a single polarization for the MI antenna. All these modes are chosen by the operator during flight.

\subsection{Digital processing unit:}

The digital processing unit is shown in detail in Figure 5. After sampling the IF signal at 360 $\mathrm{MHz}$, the first step of the real time on-board processing is the range compression. The raw signal is poorly resolved due to the long time impulse. Yet, as the transmitted signal is a chirp, a specific signal processing, called deramping process (simple convolution by a replica signal) delivers the well resolved signal.

The second step concerns the decimation stage. As can be seen in Table 2, the analysis band, which corresponds to the maximum beat frequency resulting from the deramping processing, is $54 \mathrm{MHz}$ at most. Therefore a decimation factor of 6 is applied in order to reduce the complex sampling frequency from 360 to $60 \mathrm{MHz}$, and the low pass filter was designed to cutoff at 54 MHz.

The third step consists in an FFT processing providing the pulse response corresponding to the backscattered power as a function of range.

The last step is the coherent integration of the complex samples over $1 \mathrm{~ms}$ for each range gate. We choose to use the pulse pair processing technique (Zrnic, 1977), which provides amplitude and phase of the mean signal with an efficient noise reduction. The maximum amplitude of the Doppler velocity that can be measured (corresponding to a phase of the complex signal equal to $\pi$, is $V_{\text {Dmax }}=\lambda /(4 P R I)$, where $\lambda$ is radar wavelength and PRI is pulse repetition interval. From the values of PRI listed in Table 2, it follows that $\mathrm{V}_{\text {Dmax }}$ is at least equal to $103 \mathrm{~m} / \mathrm{s}$, which is always larger than the line of sight velocity for the usual velocity of the plane $(\approx 100 \mathrm{~m} / \mathrm{s})$.

The radiometric data (I\&Q signals integrated on $1 \mathrm{~ms}$ ) and the ancillary data (aircraft attitudes, GPS time, ...) are recorded at the same rate of $1 \mathrm{kHz}$.

\subsection{Verification and Calibration}

Internal calibrations and measurements have been performed in laboratory, involving an internal signal from noise diode to check the stability of the receiver gain, and an internal $50 \Omega$ load to estimate the thermal noise level and to check the stability of frequency and amplitude of the reflected signal on the load (transfer function restitution). The gain and losses of the complete chain have also been measured, and adequate corrections are deduced from these measurements 
and applied in ground post-processing. Such tests involving noise diode and $50 \Omega$ load are also performed on board to check the stability of the instrument from flight to flight. A specific mode is used for this control (several chirp signals are transmitted and delayed sweeping all the swath). The transmitted power is measured on board every second and stored in the data frame.

To assess the absolute level of the backscattered power, an external calibration was also performed using corner reflectors (trihedral reflectors) installed on an aircraft runway, overflown by the airplane during specific flights. Those measurements yielded a bias of $-0.2 \mathrm{~dB}$ when compared to the expected backscatter power levels (see section 4.1 below).

\subsection{Expected performances on the estimation of the backscattering coefficient}

The effective Signal/Noise Ratio $\mathrm{SNR}_{\mathrm{e}}$, corresponding to the inverse of the radiometric resolution $\mathrm{K}_{\mathrm{p}}$, is given by the following relation (e., g., Ulaby et al., 1986):

$$
S N R_{e}=\frac{1}{K_{p}}=\frac{\sqrt{N_{\mathrm{int}}}}{\left(1+\frac{1}{S N R}\right)}
$$

where $\mathrm{N}_{\text {int }}$ is the number of independent samples.

The error $\delta \sigma_{0}$ on the estimation of the backscattering coefficient (expressed in $\mathrm{dB}$ ) is related to the radiometric resolution through:

$$
\delta \sigma_{\mathrm{o}}=10 \log \left(1+\mathrm{K}_{\mathrm{p}}\right)
$$

The signal is integrated coherently over $1 \mathrm{~ms}$ through on-board processing. The complex signal can then be integrated over longer time by post-processing. The objective is to estimate $\delta \sigma_{o}$ within a $0.2 \mathrm{~dB}$ maximum uncertainty. Table 3 presents the theoretical errors on the estimation of the backscattering coefficient depending on the SNR and the number of independent samples. The results are calculated following different integration times for the two antennae for the $3000 \mathrm{~m}$ altitude mode. Those results show that it is necessary to integrate the signal over $30 \mathrm{~ms}$ at least for both antennae to reach the objective of $0.2 \mathrm{~dB}$ estimation error.

\subsection{Antenna performances}

The antenna design was constrained by the use of a quartz window of $40 \mathrm{~mm}$ thickness, which was introduced to allow the whole radar system, including the antennae, to be within the aircraft body under cabin pressure. Efforts have been made through many numerical and laboratory tests to reduce the impact of this window on the antenna pattern. The IETR laboratory ("Institut d'Electronique et de Télécommunications de Rennes") in charge of antenna design worked on the optimization of the weighting of each patch using the convex optimization method (Fuchs and Fuchs, 2010) to get a main beam with the required specifications (aperture angles and direction). However, after installation on-board, the first in-flight measurements on corner reflectors in February 2012 revealed that for the MI antenna, the radiation pattern is significantly distorted. An external view of the antenna system mounted on the aircraft is shown in Figure 6. The quartz window is supported by a circular metallic ring, which can be seen in Figure 6 and is at the 
origin of a diffraction effect, presumably responsible for this distortion. This drawback prevents us from obtaining reliable results in term of absolute $\sigma^{\circ}$ with the MI antenna, even though relative variations of $\sigma^{\circ}$ and Doppler measurements are not affected by this problem. Due to this antenna pattern distortion, the results from the MI antenna will not be presented in this paper.

In contrast, the radiation pattern of the LI antenna, whose field of view is nearer to the nadir direction, is not impacted by this metallic ring. This could be checked from the calibration flights over corner reflectors, which yielded radiation patterns of the LI antenna very close to those obtained from laboratory tests, both in terms of shape and absolute level (bias $-0.2 \mathrm{~dB}$, rms difference $0.4 \mathrm{~dB}$ ) as will be seen in section 4.1 below.

The advantages of this design with a beam pointing through a quartz window are the ease of instrument integration in the airplane, and the fact that the overall instrument is under aircraft pressure. However the problem encountered with the MI antenna leads us to prepare an upgrading of the radar with a new design where this window will be removed. The modifications are presently under progress.

\section{Description of the campaigns}

The first scientific use of KuROS occurred in March-April 2013 in the context of field campaigns carried out for two meteo-oceanographic programs. The first one is the HyMeX program (HyMeX = Hydrological cycle in the Mediterranean Experiment, see Drobinski et al., 2013) in the North part of Mediterranean sea, while the second one is the PROTEVS project devoted to observation and modelling of current, waves and storm surge with a campaign in the Iroise sea close to the Brittany coasts of France.

HyMeX is an international cooperative project organized with the aim of improving the understanding and quantification of the hydrological cycle and related processes in the Mediterranean, with emphasis on high-impact weather events. One of the scientific goals is to improve our understanding of intense sea-atmosphere interactions. To address this question, an experimental multi-scale strategy has been designed with special observation periods (SOP) imbedded within enhanced observation periods and a long-term observation period. SOP \#2 was organized in February-March 2013 in the North-West of the Mediterranean sea to study intense air-sea exchanges and dense water formation. This region is exposed to regional offshore intense winds called Mistral (Northely winds) and Tramontane (Northwesterly winds), usually associated with an anticyclonic system over west of France and a cyclonic system over the Gulf of Genova. These situations generate high sea-state under fetch-limited conditions, and in winter and beginning of spring they also often generate oceanic convection. From March $4^{\text {th }}$ to April $15^{\text {th }}$ 2013, wind blew as Mistral and/or Tramontane for a total of more than 18 days by periods of 2 to 3 days of continuous strong (10 to $25 \mathrm{~m} / \mathrm{s})$ offshore winds. From March $4^{\text {th }}$ to March $6^{\text {th }}$ a cyclonic system located east of Spain generated strong easterly winds $(10-20 \mathrm{~m} / \mathrm{s})$ in the North part of the Gulf of Lion basin.

During this SOP \#2 experiment in situ measurements (from ship, moored buoys, drifters) have been carried out. A meteo-oceanic buoy (called Lion buoy), moored in the Gulf of Lion (Northwest of the Mediterranean sea) provides surface parameters (10-m wind, directional spectra of surface gravity waves, air and sea temperature, atmospheric pressure) in an offshore region. Coastal buoys (Azur, Banyuls, Leucate..) provide additional data of significant wave height, and mean wave period, and for some of them surface wind, air and sea temperature. 
During HyMeX, the French research aircraft ATR42 flight-time was shared between two research teams and two types of measurements: in situ measurements in the boundary layer to provide mean and turbulent atmospheric quantities, and remote sensing measurements of the oceanic surface with KuROS. Because the optimal flight levels for KuROS are between 2000 and 3000 $\mathrm{m}$, each flight period was divided in several sub-periods, some of them dedicated to KuROS measurements with the 2000 and 3000 flight-levels. A total of 11 flights with KuROS data has been achieved during HyMeX. Table 4 gives the list of flights, the KuROS measurements during these flights, and the corresponding wind and wave conditions at the Lion buoy. An example of flight plan during a Tramontane event (northwesterly flight) is shown in Figure 7.

The other field experiment during which KuROS was involved is PROTEVS (Prévision Océanique, Turbidité, Ecoulement, Vagues et Sédimentologie). This experiment was designed and carried out by the french naval service SHOM (Service Hydrographique et Océanographique de la Marine). It is devoted to the study of wave/current interactions and storm surge conditions in the coastal region of Brittany. The goal is to improve the modelling of current and waves with the HYCOM model (HYbrid Coordinate Ocean Model, see http://hycom.com) and the wave model WAVEWATCH III ( http://polar.ncep.noaa.gov/waves/index2.shtml), respectively. The area is characterized by very strong tide currents, complex bathymetry and coastal line, as well as frequent occurrence of long swell generated by Atlantic storms. Five Datawell ${ }^{\odot}$ directional wave riders were moored by SHOM in the area as well as several current sensors which can also provide information on surface waves.

During this experiment, KuROS was flown over the area (see Figure 8) with 2 flights on the same day (February $11^{\text {th }}, 2013$ ) separated by about 4 hours. The first data set (11:11-13:50 UTC) was collected after low tide (which occurred 10:47 UTC), with the flight pattern of Figure 8 described twice (once at 2000 and once at $3000 \mathrm{~m}$ altitude). The second data set (15:53 to 16:59 UTC) was collected just before high tide (16:50 UTC) with the flight pattern of Figure 8 at 3000 $\mathrm{m}$ altitude. The situation of February $11^{\text {th }}, 2013$ corresponds to a Northwest swell with significant wave height of up to $6.8 \mathrm{~m}$, a tide index of 107 and moderate wind $(\approx 6 \mathrm{~m} / \mathrm{s})$.

\section{Checks of the performance of the instrument from flight data:}

\subsection{Calibration flights over corner reflectors:}

Five trihedral reflectors ( $40 \mathrm{~cm}$ edge, $32.5 \mathrm{dBm}^{2}$ radar cross-section) were installed over a concrete surface, separated by about $50 \mathrm{~m}$ in the along-flight direction and $10 \mathrm{~m}$ in the across-track direction. Such a lay out was chosen to spread the 5 reflectors over the KuROS footprint while flying at about $450 \mathrm{~m}$ above the surface. Several overpasses with KuROS have been carried out, with the KuROS antennae pointed either forward or backward with respect to the aircraft route. During the flight, in coordination with the radar operators onboard the plane, ground operators adjust manually the tilt of the trihedral reflectors toward either $14^{\circ}$ or $40^{\circ}$ depending upon whether the LI or MI antenna is tested. This procedure enables us to assess the antenna radiation pattern and the absolute calibration.

Five overflights of the reflector system were performed during flight 12, but for one of them the flight track was not properly aligned with the system of reflectors, and for another one the aircraft altitude was varying during overflight rendering the data difficult to interprete. Only the three remaining overflights were quite successful and were therefore retained for analysis. For each of those successful overflights, due to the $10 \mathrm{~m}$ across-track separation of the 5 reflectors, the reflector which is located the closest to the flight track yields the highest power backscatter 
signature, and only that one is retained for calibration analysis. The results are shown in Figure 9. We also display the antenna radiation pattern obtained from the anechoic chamber measurements (blue line), and its Gaussian fit (red dashed line), with maxima coinciding with the $32.5 \mathrm{dBm}^{2}$ radar cross section of the triedral reflectors at boresight. It may be seen that the retrieved shape and level of the antenna radiation pattern are remarkably consistent with the twoway radiation pattern obtained from laboratory tests. Over the $3 \mathrm{~dB}$ interval $\left(\approx 7^{\circ}-20^{\circ}\right)$, the bias and $\mathrm{rms}$ difference between in-flight data and laboratory data are $-0.2 \mathrm{~dB}$ and $0.4 \mathrm{~dB}$, respectively. For incidence angles above $\approx 28^{\circ}$, however, the lobe deviates radically from the Gaussian pattern, due to the combined effects of secondary lobes, contribution of the ground to the backscattered power, and poor SNR ratio.

The overflights over trihedral reflectors can also be used to check the consistency of the Doppler velocity measured by the radar. This is illustrated in Figure 10, where the Doppler velocity measured by the radar is compared with the line-of-sight velocity deduced from the aircraft inertial navigation system. Since the aircraft velocity is different from one overflight to the other, it would be meaningless to compare velocity measurements from different overflights, and therefore the data from only one overflight are displayed in Figure 10, and only the data from the three most centered trihedrals (those yielding the highest power patterns) are shown. It may be seen that the quality of the retrieval of the Doppler velocity is virtually independent of the incidence angle between $7^{\circ}$ and $20^{\circ}$. Over that range of incidences, after averaging over the three overflights reported in Figure 9, the average bias and rms difference for velocity are $0.4 \mathrm{~m} / \mathrm{s}$ and $0.5 \mathrm{~m} / \mathrm{s}$, respectively. Below $6^{\circ}$, due to the low altitude used for calibration flights $(\approx 500 \mathrm{~m})$, the uncertainty of the altitude retrieval limits the accuracy of the incidence angle assigned to each range gate, which explains the increased dispersion of the data. Above $\approx 31^{\circ}$ incidence angle, the SNR of the radar signal attains a threshold below which the Doppler velocity retrieval suddenly fails.

\subsection{Assessment of the number of post-integrations to perform:}

We have seen in section 2.4 that the signal is integrated coherently over $1 \mathrm{~ms}$ by on-board processing, and that the complex signal can then be integrated over longer time by postprocessing. Tests were performed with coherent and incoherent post-processing, with varying numbers of post-integrations. Figure 11 is an example of the power profile obtained over the sea from an altitude of 2000 meters. The power profile integrated coherently over $1 \mathrm{~ms}$ is compared with the ones obtained by coherent and incoherent post-integration over $33 \mathrm{~ms}$. Coherent postintegration over $\mathrm{N}$ samples should reduce the noise by $5 \log _{10} \mathrm{~N}(\mathrm{~dB})$, while keeping the signal level unaffected. As expected, comparison of the raw and coherently integrated data displayed in Figure 11 follows this theoretical behaviour. From various tests performed with different integration times, such post integration time of $33 \mathrm{~ms}$ was chosen for the results presented in this paper, providing a reasonable compromise between noise level and effective horizontal resolution (taking into account the displacement of resolution cells). In the worst case of a forward or backward viewing direction for an aircraft velocity of $100 \mathrm{~m} / \mathrm{s}$, the footprint displacement during such integration time is smaller than a range gate. As concerns the azimuthal shift, assuming for example a spin rate of the antenna of 4 rotations per minute (equivalent to $24^{\circ} / \mathrm{sec}$ ), over the $33 \mathrm{~ms}$ post-integration time the antenna will rotate by $0.79^{\circ}$ with respect to the vertical axis. For an incidence angle $\theta=14^{\circ}$, in the antenna frame this corresponds to an azimuth displacement of 
the antenna pattern by $0.79^{\circ} x \sin \theta=0.19^{\circ}$, which is no more than about $3 \%$ of the two-way azimuthal antenna beamwidth.

\section{First results of $\sigma^{\circ}$ and Doppler velocity}

\subsection{Analysis of the behavior of the $\sigma^{\circ}$ signal}

Figure 12 shows an example of the measured normalized radar cross section $\sigma^{\circ}$ averaged over azimuth as a function of incidence angle. The absolute calibration of the data was obtained from laboratory measurements and assessed from the flights over corner reflectors by the method described in section 4.1. For this example the wind speed was $9 \mathrm{~m} / \mathrm{s}$ and the significant wave height was $\mathrm{Hs} \approx 5.3 \mathrm{~m}$. The standard deviation of $\sigma^{\circ}$ over an incidence angle interval of $1^{\circ}$ (indicated as error bars in Figure 12) is of the order of $\pm 1.5 \mathrm{~dB}$ to $\pm 2 \mathrm{~dB}$ depending on incidence angle. This relatively high standard deviation is due to the fact that $\sigma^{\circ}$ is deeply modulated by the sea waves, and those modulations themselves will be used below to retrieve the sea wave spectrum. The average $\sigma^{\circ}$ displayed in Figure 12 may be compared to $\sigma^{\circ}$ predicted by empirical Geophysical Model Functions (GMF) which have been produced from satellite data. The GMF by Freilich and Vanhof (2003) gives a modeled $\sigma^{\circ}$ as a function of wind speed, and was built from observations of TRMM PR Ku band radar for incidence angles between $0^{\circ}$ and $18^{\circ}$. This model function is based on the quasi-specular approach in the limit of Gaussian isotropic sea surface slope distribution, which is expected to be accurate for microwave scattering for $0 \leq \theta \leq 15^{\circ}$. A quadratic multi-parameter fit to TRMM PR data sorted according to wind and significant wave height was also performed over the incidence angle range from $5^{\circ}$ to $18^{\circ}$, from the large collocated data base compiled by Tran et al. (2007), and the result for this wind and wave situation is also indicated in Figure 12 as + signs. Finally, the GMF by Wentz and Smith (1999) (thick solid line in Figure 12) is based on the Ku band NSCAT scatterometer data, which were available only for $\theta \geq 18^{\circ}$. It may be seen that our measurements are consistent with the TRMM models at low incidence angles, although it is $\approx 1 \mathrm{~dB}$ above the NSCAT model near $20^{\circ}$ incidence. Such a difference is not significant given the difficulty to perform absolute intercalibrations of GMFs obtained from different satellites, as was shown by Caudal et al. (2005).

The azimuthal variation of $\sigma^{\circ}$ can be easily studied due to the rotation of the antenna. Figure 13 shows the azimuthal variation of $\sigma^{\circ}$ for the case of flight 18 , for an incidence angle of $20^{\circ}$. The display includes one minute of data, which corresponds to 2.4 rotations of the antenna. A least square fit to the data is also displayed involving 5 parameters (a constant and the phases and amplitudes of the two first harmonics). The azimuthal variation of $\sigma^{\circ}$ from Wentz and Smith's (1999) GMF is also shown for comparison. Apart from the offset of average $\sigma^{\circ}$ already identified in Figure 12, the amplitude of the azimuthal modulation of the KuROS data fitted by two harmonics $( \pm 1.1 \mathrm{~dB})$, is fairly close to the amplitude obtained from Wentz and Smith's (1999) model $( \pm 0.9 \mathrm{~dB})$. For this example, the first maximum of the fitted curve occurs for an azimuth of $125^{\circ}$, which differs by no more than $5^{\circ}$ from the average wind direction given by the buoy $\left(\approx 120^{\circ}\right)$. In Figure 13 one may also notice the large variations $( \pm 4 \mathrm{~dB})$ of the data around the fitted line. This is due to the small size of the elementary backscattering surface in the range direction, which is determined by the pulse-limited range resolution of the radar $(1.5 \mathrm{~m})$, yielding an horizontal resolution of $\approx 6.2 \mathrm{~m}$ for $14^{\circ}$ incidence angle, which is much smaller than the typical wavelength of the dominant sea waves (a few hundred meters). The surface tilt variations due to those large-scale sea waves thus produces the deep modulations of $\sigma^{\circ}$ observed in Figure 13. 
Such modulations of $\sigma^{\circ}$ can be used to measure sea wave directional spectra through the method described in section 5.2 below.

\subsection{Measurement of the sea wave spectrum}

The analysis of the modulations of radar reflectivity as a function of radial distance permits us to compute the directional sea wave spectrum along the direction of observation, while the rotation of the antenna around the vertical axis permits to explore all the azimuthal directions. The theory underlying this measurement technique was given by Jackson et al.(1985a), and is briefly reviewed here. For each azimuthal direction $\varphi$ of the antenna, positions on the mean sea surface may be defined by their horizontal local coordinates $\mathrm{x}$ and $\mathrm{y}$, where $\mathrm{x}$ is horizontal distance along the antenna pointing direction, and $\mathrm{y}$ is along the azimuth direction. The elementary backscatter cross-section $\sigma$ is given by $\sigma=\sigma^{\circ} \mathrm{A}$, where $\mathrm{A}$ is the area contained within a radar range gate. The presence of the large sea waves produces a tilt modulation of $\sigma$ given as

$\delta \sigma(x, y)=\sigma(x, y)-\bar{\sigma}(x, y)$

where $\bar{\sigma}(x, y)$ is the surface cross section which would occur if no large-scale wave were present. The fractional modulation $\mathrm{m}(\mathrm{x}, \varphi)$ of the cross section seen by the radar is $\delta \sigma / \sigma$ averaged laterally across the beam:

$m(x, \varphi)=\frac{\int G^{2}(y)(\delta \sigma / \sigma) d y}{\int G^{2}(y) d y}$

where $\mathrm{G}^{2}(\mathrm{y})$ is the two-way azimuth antenna radiation pattern.

In practice $\mathrm{m}(\mathrm{x}, \varphi)$ is obtained by removing a low order polynomial fit from the measured radar power profile, thus eliminating the trend and retaining only the modulations.

The sea wave polar-symmetric height spectrum $\mathrm{F}(\mathrm{k}, \varphi)$ is then obtained from the expression (Jackson et al., 1985a; Hauser and Caudal, 1996):

$$
F(k, \varphi)=\frac{L_{y}}{\sqrt{2 \pi}\left(\cot \theta-\frac{\partial \ln \sigma_{o}}{\partial \theta}\right)^{2}} \frac{1}{k^{2}} P_{m}(k, \varphi)
$$

In this expression, $\mathrm{k}, \theta$, and $\varphi$ are wavenumber, incidence angle, and azimuth, respectively. $\mathrm{L}_{\mathrm{y}}$ is a length related to the azimuthal width of the beam footprint, and $\mathrm{P}_{\mathrm{m}}(\mathrm{k}, \varphi)$ is the modulation spectrum, defined as:

$P_{m}(k, \varphi)=F T(m(x, \varphi)) \times F T^{*}(m(x, \varphi))$

where FT refers to the Fourier transform operator, and * stands for complex conjugate.

As discussed by Jackson et al. (1985a), the speckle noise of the radar technique produces a supplementary modulation of $\sigma^{\circ}$, which is included in the measured modulation spectrum, and 
this speckle noise must then be removed from the data for precise quantitative studies. In order to estimate the spectrum of the speckle noise, Hauser et al. (1992) used a semi empirical method based on the comparison between data integrated over different time intervals. Another approach was proposed by Engen and Johnsen (1995) in the context of the processing of SAR images. Those authors proposed to remove the speckle noise by computing image cross-spectra between pairs of single look SAR images separated in time. Following their approach, we replaced here the modulation spectrum $\mathrm{P}_{\mathrm{m}}(\mathrm{k}, \varphi)$ of equation (6) above by the the quantity:

$P^{\prime}{ }_{m}(k, \varphi)=\operatorname{Real}\left\{F T(m(x, \varphi, t)) \times F T^{*}(m(x, \varphi, t+\delta t))\right\}$

The time interval $\delta$ should be large enough that the speckle noise of both profiles are decorrelated, but small enough that the radar footprint is only marginally displaced during that interval. Also, preliminary post-integration of the raw $(1 \mathrm{kHz})$ data must be sufficient in order to provide a first reduction of the speckle. The interval $\delta t$ is set to twice the post-integration time to ensure that the speckle noises of both profiles of equation (7) are well decorrelated. Here we requested a displacement of the footprint by less than $10 \%$ over the time interval $\delta$. From 3000 $\mathrm{m}$ altitude with 4 rotations per minute this implies that $\delta \mathrm{t} \leq 80 \mathrm{~ms}$. Several trials were done with $\delta \mathrm{t}$ between 30 and $80 \mathrm{~ms}$ and gave very similar results (the standard deviation of significant wave heights retrieved with those different assumptions was of the order of 3 to $5 \mathrm{~cm}$, for $2000 \mathrm{~m}$ as well as $3000 \mathrm{~m}$ flights). Since the post-integration time used routinely is $33 \mathrm{~ms}$, in this paper we use $\delta \mathrm{t}=66 \mathrm{~ms}$.

Nevertheless, due to imperfect correlation between the sea wave signals at times $t$ and $t+\delta t$, the computed $\mathrm{P}_{\mathrm{m}}(\mathrm{k}, \varphi)$ happens to be negative on some scarce occurrences. Since the sea wave spectrum should be a positive definite quantity, those values are artificially set to zero. This has virtually no effect on the retrieved significant wave height. The results obtained by this method are fairly consistent with speckle estimates obtained using Hauser et al's (1992) approach. The results presented below have been obtained by using this cross-spectral approach.

As an example, Figure 14 shows a comparison between the omnidirectional sea wave spectrum measured by the Lion buoy and by KuROS (corrected from the speckle noise) for the flight of 6 march 2013. The hourly spectrum of the buoy is taken at 12:00 (the closest time to the overflight), and the KuROS spectrum just before and just after the overflight are shown. Although the sea wave field was rather inhomogeneous, the radar measurements are consistent with the hourly buoy measurement. The peak frequency observed by both KuROS and the buoy is $\approx 0.09 \mathrm{~Hz}$. The significant wave height $\mathrm{H}_{\mathrm{S}}$ is obtained by integrating the directional spectrum $\mathrm{F}(\mathrm{k}, \varphi)$ of equation $(5)$ over the wavenumber space:

$H_{S}=4 \sqrt{\int_{-\pi}^{\pi} \int_{0}^{\infty} F(k, \varphi) k d k d \varphi}$

The $\mathrm{H}_{\mathrm{S}}$ measured by the buoy is $5.3 \mathrm{~m}$, while the $\mathrm{H}_{\mathrm{S}}$ from the radar is $5.1 \mathrm{~m}$ and $5.6 \mathrm{~m}$ before and after the overflight, respectively.

Figure 15 shows an example of the sea wave directional slope spectrum $k^{2} F(k, \varphi)$ measured by the radar. Such a spectrum was obtained from a data set of 30 seconds, which corresponds to a little more than a rotation of the antenna in that case. Due to the $180^{\circ}$ ambiguity of the slope 
spectrum analysis, only a symmetrized $2 \mathrm{D}$ spectrum is presented here. The question of the removal of this $180^{\circ}$ ambiguity will be addressed in section 5.3 below.

A more systematic comparison between KuROS and sea wave buoy data during overflights has been performed in order to check the ability of KuROS to identify spectral peaks, and to refine the calibration of the instrument in terms of $\mathrm{H}_{\mathrm{S}}$. The results including the overflights performed during the HyMeX campaign which are listed in Table 4, are shown as scatter plots in Figure 16. As concerns the sea wave peak direction, the $180^{\circ}$ ambiguity has been removed by reference to the buoy data. As indicated in Figure 16, the correlation coefficient $\mathrm{C}$ between the buoy and radar measurements are particularly good for for $\mathrm{Hs}(\mathrm{C}=0.93)$, and correlation is somewhat weaker for both peak direction $(\mathrm{C}=0.81)$ and peak frequency $(\mathrm{C}=0.81)$. It may be noted that buoys provide sea wave spectra integrated over periods of the order of half an hour at one unique location, and thus the consistency between the wave parameters inferred from buoy and radar in Figure 16 is quite satisfactory given the spatio-temporal inhomogeneity of the sea wave field. It may be noted, overall, that KuROS is remarkably efficient to identify spatial inhomogeneities of the wave field occurring in limited fetch situations, which would not be attainable from a unique buoy.

\subsection{Analysis using the Doppler signal}

As the KuROS antenna is rotating around a vertical axis, the line-of sight velocity is alternatively positive or negative, depending upon the azimuthal orientation of the antenna. Typical velocities of the aircraft are of the order of $100 \mathrm{~m} / \mathrm{s}$, and thus for incidence angles smaller than $20^{\circ}$ the Doppler velocity related to the aircraft motion ranges between $-35 \mathrm{~m} / \mathrm{s}$ and $+35 \mathrm{~m} / \mathrm{s}$. An example of the Doppler signal over the sea is shown in Figure 17. As can be seen, the most important feature is the sinusoidal variation of the Doppler velocity as the antenna is rotating. From the analysis of measurements of Doppler velocities obtained with different orientations of the aircraft with respect to the wind and wave system, the average Doppler velocity signatures that we obtain are consistent with those expected from the aircraft motion, except that we needed to correct the antenna rotation angle by a systematic offset of $4^{\circ}$. This offset, presumably due to a misalignment of the antenna beam, has been systematically corrected from the data presented henceforth in this paper.

In order to study the velocity signature of the surface, this component related to the aircraft velocity has to be removed by using the ancillary velocity data given by the inertial navigation system (INS) of the plane. The residual Doppler shift or Doppler velocity anomaly, of interest here, is related to the kinematics of the sea surface. Note that the rms errors of the velocity components given by the INS are smaller than $3 \mathrm{~cm} / \mathrm{s}$. Most of this error is related to the low rate of the INS data $(25 \mathrm{~Hz})$ while the KuROS data are recorded at a rate of $1 \mathrm{kHz}$. However, since only the spatial modulations of velocities within each footprint will be used in this paper, those errors will have negligible effect.

\subsubsection{Ambiguity removal of the measured sea wave directional spectrum through the orbital velocity of sea waves}

Due to the changing orbital velocity along the phase of long surface waves, the front faces (as seen by the radar) of long waves propagating away from the radar have a positive line-of-sight velocity anomaly (orbital velocity directed away from the radar). The front faces of these waves are tilted toward the radar so that the backscattered power is also greater. The modulations of 
NRCS and Doppler velocity are therefore correlated. In contrast, in a situation of long waves propagating toward the radar, the Doppler anomaly signatures would be inverted and one would thus observe an anti-correlation between NRCS and Doppler modulations. Thompson et al. (1991) obtained a clear signature of such a correlation between wave orbital velocities and normalized radar cross section (NRCS) for Ku band radar at an incidence angle of $20^{\circ}$.

Following this approach, we will assume that the orbital velocities dominate the wave related velocity modulations. The correlations between the $\sigma^{\circ}$ and velocity modulations are thus expected to be either positive or negative depending upon whether the waves are travelling away from or toward the radar. The sign of this correlation can be obtained for each spectral component by computing the cross-spectrum between the fluctuations of $\sigma^{\circ}$ and velocity :

$C_{1}(k, \varphi)=F T\left(\frac{\delta \sigma_{o}}{\sigma_{o}}(x, \varphi)\right) \times F T^{*}(\delta V(x, \varphi))$

where $\mathrm{x}$ is the horizontal distance along the direction of observation, FT is the Fourier Transform operator along the $\mathrm{x}$ dimension, and ${ }^{*}$ denotes the complex conjugate. $\delta \sigma^{\circ}$ and $\delta \mathrm{V}$ are the $\sigma^{\circ}$ and velocity modulations. To obtain them, one firstly removes the radial velocity due to airplane from the velocity signal (thus yielding the residual velocity). Then one computes the smoothed radial profiles of $\sigma^{\circ}$ and residual velocity, which are further removed to yield the modulations $\delta \sigma^{\circ}$ and $\delta \mathrm{V}$.

From the computed cross-spectrum $\mathrm{C}_{1}(\mathrm{k}, \varphi)$, each sea wave Fourier component can be ascribed a propagation direction away from the radar if $\operatorname{Real}\left(\mathrm{C}_{1}(\mathrm{k}, \varphi)\right)>0$, or toward the radar if $\operatorname{Real}\left(\mathrm{C}_{1}(\mathrm{k}, \varphi)\right)<0$. Figure 18 displays the result of the directional sea wave spectrum obtained by this method, and corresponding to the folded spectrum which was given above in Figure 15. The main wave train of Figure $\mathbf{1 8}$ is seen clearly to be propagating toward south-West. This is fully consistent with the direction of propagation of the sea waves as measured by the buoy, as will be shown below in section 5.3.2

\subsubsection{Comparison with ambiguity removal performed from the phase velocity of sea waves}

It may be interesting to compare the method used above to remove the $180^{\circ}$ ambiguity of the directional spectra, to the approach which is used to retrieve ocean wave spectra from crossspectra of SAR images (Engen and Johnsen, 1995). In the same manner as done above in section 5.2 , the cross-spectrum between two radar power profiles separated by some time lag $\Delta \mathrm{T}$ can be computed, and the phase velocity of the sea wave can be deduced by analyzing its argument. The cross-spectrum may be written:

$$
C_{2}(k, \varphi)=F T\left(\frac{\delta \sigma_{o}}{\sigma_{o}}(x, t)\right) \times F T^{*}\left(\frac{\delta \sigma_{o}}{\sigma_{o}}(x, t+\Delta T)\right)
$$

For each wavenumber $\mathrm{k}$, the phase velocity $\mathrm{V}_{\mathrm{p}}$ of the sea wave propagating along the horizontal direction of observation may be obtained through: 
$V_{P}(k, \varphi)=\frac{\delta p}{k \Delta T}-V_{A H}(\varphi)$

where $\delta p$ is the phase difference between the Fourier transforms of $\delta \sigma_{0} / \sigma_{o}$ at times $t$ and $t+\Delta T$, and $\mathrm{V}_{\mathrm{AH}}$ is the horizontal component of the aircraft velocity along the direction of observation. From equation (10) this may be rewritten :

$V_{P}(k, \varphi)=\frac{1}{k \Delta T} \arctan \left(\frac{\operatorname{Im}\left(C_{2}(k, \varphi)\right.}{\operatorname{Re}\left(C_{2}(k, \varphi)\right.}\right)-V_{A H}(\varphi)$

From the computed cross-spectrum $\mathrm{C}_{2}(\mathrm{k}, \varphi)$, each sea wave Fourier component can thus be ascribed a propagation direction away from the radar if $\mathrm{V}_{\mathrm{P}}(\mathrm{k}, \varphi)>0$, or toward the radar if $\mathrm{V}_{\mathrm{P}}(\mathrm{k}, \varphi)<0$. This method thus permits to remove the direction ambiguity by merely comparing two snapshots of the surface obtained at times $t$ and $t+\Delta t$, without the need to use the Doppler measurement.

The choice of the time lag $\Delta \mathrm{T}$ is rather arbitrary. In section 5.2 (equation (7)), a short time lag of $66 \mathrm{~ms}$ was chosen in order to eliminate the speckle noise from two profiles containing virtually the same signal. Here instead we wish to identify the displacements of the wave trains, therefore the time lag $\Delta \mathrm{T}$ should be large enough that a significant phase shift is measured between times $\mathrm{t}$ and $\mathrm{t}+\Delta \mathrm{T}$, but small enough that the area illuminated by the radar is only marginally modified over that time interval. The illuminated area is moving under the combined effect of the aircraft velocity and antenna rotation. As a consequence the correlation between radial features obtained at times $t$ and $t+\Delta T$ is imperfect and therefore the cross-spectrum $C_{2}(k, \varphi)$ of equation (10) is reduced, rendering the estimation of the sea wave phase velocity more noisy as $\Delta \mathrm{T}$ is increased. Several trials were performed with different values of $\Delta \mathrm{T}$, and the optimum was obtained for $\Delta \mathrm{T}$ of a few tenths of a second, although the result is only weakly dependent upon the choice made for $\Delta \mathrm{T}$ between $0.2 \mathrm{sec}$ and $0.4 \mathrm{sec}$. In this paper we take $\Delta \mathrm{T}=0.4 \mathrm{sec}$, which yields results which are the closest to the buoy data (see below).

Figure 19 displays the result of the disambiguated directional sea wave spectrum obtained by this method, and corresponding to the same case as Figure 18. The overall direction is similar to the one retrieved from the orbital velocity (Figure 18), with a main component propagating toward south-west. However, the retrieved directions are more scattered, with an increased number of spectral components propagating along the opposite direction. The question is then whether the scarce components propagating toward North-East in Figure 19 are real features, or an artifact due to the retrieving process.

In order to address this question, we compared both retrieved spectra of Figure 18 and Figure 19 with the ones deduced from the directional Lion buoy. For each wavenumber, however, the data from the directional buoy only consist of a power level and two complex harmonics, and direct comparison with the much more detailed directional spectra obtained from KuROS is therefore not relevant. We therefore computed the two first harmonics of the spectra obtained from KuROS, and then compared them directly to the buoy data. For each wavenumber, the directional spreading function of the sea wave spectrum may be written :

$D(\varphi)=\frac{1}{2 \pi}\left(1+2\left(a_{1} \cos \varphi+b_{1} \sin \varphi+a_{2} \cos 2 \varphi+b_{2} \sin 2 \varphi\right)\right)$ 
where $\varphi$ is azimuth, while $a_{1}, b_{1}, a_{2}, b_{2}$ are real coefficients which are fitted to the data. The sets of coefficients $\left(a_{1}, b_{1}\right)$ and $\left(a_{2}, b_{2}\right)$ define the first and second complex harmonics, respectively. With respect to a rotation of $180^{\circ}$, the first harmonic is antisymmetric while the second harmonic is symmetric, and thus the secondary component directed toward North-East seen in Figure 19 should correspond to a significant increase of the second harmonic. Validation of the ambiguity removal method will depend upon whether or not the buoy data show this increased second harmonic. To address this point, Figure 20 displays the ratio $\rho=r_{2} / r_{1}$ between the amplitudes of

the second and first harmonics, $r_{1}=\sqrt{\left(a_{1}^{2}+b_{1}^{2}\right)}$ and $r_{2}=\sqrt{\left(a_{2}^{2}+b_{2}^{2}\right)}$. It can be seen that for the set of wavenumbers sampled by the radar (from 0.02 to $0.3 \mathrm{rad} / \mathrm{m}$ ), the ratio $\rho$ deduced from orbital velocity (solid line in Figure 20) exhibits moderate fluctuations, with an average of $\rho \approx 0.61$ which is close to the average ratio $\rho$ obtained by the buoy $(\langle\rho>\approx 0.55)$. As a comparison, the ratio $\rho$ deduced from phase velocity in the optimal case $(\Delta \mathrm{T}=0.4 \mathrm{sec}$, dashed line in Figure 20) is much more scattered, with a much larger average value $(\langle\rho>\approx 1.14)$. This indicates that the secondary North-Eastern component appearing in Figure 19 is not confirmed by the buoy data, whereas the spectrum of Figure 18 is fairly consistent with the buoy data.

We performed such comparisons in a more systematic manner from overflights of the buoy performed on 6 different days with different wind and sea conditions. For each of those 6 cases, we computed the difference $\Delta \rho(\mathrm{k})$ between ratios $\rho$ obtained by the radar and by the buoy at each wavenumber $\mathrm{k}$ from 0.02 to $0.3 \mathrm{rad} / \mathrm{m}$. From this we deduced the rms average of $\Delta \rho(\mathrm{k})$ over $\mathrm{k}$ (hereafter noted $\langle\Delta \rho>$ ). In all the 6 cases studied the method based on orbital velocity gave smaller $\langle\Delta \rho>$ than the method based on phase velocity. The average value of $<\Delta \rho>$ over the 6 overflights was found as 0.79 when the orbital velocity method was used, while it was as high as 1.61 when the phase velocity method was used.

The method based on orbital velocity (using the Doppler signature) thus appears to be more efficient to remove the $180^{\circ}$ ambiguity on the sea wave directional spectrum retrieved by KuROS, and should be preferred to the method using the phase velocity.

\section{Conclusion}

The new airborne Ku-band radar KuROS provides measurements of radial profiles of the normalized radar cross section $\sigma^{\circ}$ over the sea surface at low and intermediate incidences. The antenna system is mounted on a platform rotating around a vertical axis in order to explore the different azimuthal directions. The spectrum of ocean waves with wavelengths larger than a few tens of meters is obtained by analyzing the modulations of the radial profiles of $\sigma^{\circ}$. As the antenna is rotating, the different azimuthal directions are explored, allowing to retrieve the directional spectrum of sea waves. In addition to measuring $\sigma^{\circ}$, KuROS has the ability to measure the Doppler velocity of the radar echo, by means of the pulse pair technique. This innovative implementation permits to explore the characteristics of the kinematics of the sea surface, and to remove the $180^{\circ}$ ambiguity inherent to the principle of measurements based on the analysis of slope modulations of $\sigma^{\circ}$ by a low incidence real aperture radar.

In order to address the question of measuring both wind and waves, the KuROS radar system includes two antennas, one probing a range of incidence angles around $14^{\circ}$ (low incidence antenna or LI antenna), and another antenna probing incidence angles around $40^{\circ}$ (medium incidence antenna or MI antenna). However, the calibration flights over corner reflectors revealed 
a significant distortion of radiation pattern of the MI antenna, presumably due to diffraction by a metal collar used to adjust the antenna system within the body of the plane, and for this reason only the results from the LI antenna have been presented in this paper.

The KuROS radar has participated to two field experiments in 2013: the HyMeX program in the North of Mediterranean sea, and the PROTEVS campaign in the Iroise sea close to the Brittany coasts of France. We present the implication of KuROS within these field campaigns, and give the first results from the observations performed during these campaigns.

Sea wave directional spectra computed from the radar observations during the HyMeX campaign, were compared to the sea wave spectra produced by the Lion directional buoy moored in the Mediterranean basin. The speckle noise was removed from the data following the approach by Engen and Johnsen (1995), by computing cross-spectra between radar power profiles separated by some time lag $\delta$ t taken as $66 \mathrm{~ms}$. The data are consistent both in terms of significant wave height $\mathrm{H}_{\mathrm{s}}$ and main features of the wavenumber spectrum. As concerns the azimuthal distribution, two methods were tested in order to remove the $180^{\circ}$ ambiguity of the radar derived directional spectrum. The first method consists in computing the cross-spectrum between the modulations of $\sigma^{\circ}$ and Doppler velocity, which permits to remove the ambiguity by analyzing the sign of the correlation between sea surface slope and orbital velocity. The second method consists in computing the cross-spectrum between the modulations of $\sigma^{\circ}$ between two radar power profiles separated by some time lag $\Delta \mathrm{T}$, taken as a few tenths of a second. After removing the velocity of the aircraft, the phase of this cross-spectrum permits to deduce the phase velocity of sea waves in the terrestrial reference frame, whose sign yields the direction of propagation toward or away from the radar. The sea wave directional spectra disambiguated by both methods are then compared with the directional spectrum produced by the Lion buoy. From this analysis, we conclude that the method based on orbital velocity (using the Doppler signature) is more efficient to remove the $180^{\circ}$ ambiguity on the sea wave directional spectrum retrieved by KuROS, and should be preferred to the method using the phase velocity.

In the future we intend to use KuROS as a tool for geophysical studies involving the spatiotemporal evolution of the sea wave system in heterogeneous situations. In the context of the preparation of the future CFOSAT space mission, the cross-spectral method that we employed successfully to remove the speckle noise from the sea wave spectrum will permit us to study in more detail the behavior the speckle noise in various wind and wave conditions, in order to be able to remove it with best accuracy from the satellite data. Other studies will also be devoted to the estimate of the tilt velocity bias which affects the Doppler signal (Chapron et al., 2005). Although the CFOSAT mission is not intended to have the Doppler measurement capability, the Doppler issues addressed in this paper with airborne radar will hopefully be useful to help defining future satellite missions for observing the ocean surface.

Acknowledgments. The authors wish to thank the staff of the radar team at LATMOS for their involvement in the development and operation of KuROS, and in particular Laurent Chardenal, Romain Coulomb, Eric d'Almeida, Laurent Lapauw, Nicolas Pauwels, Jean-Pierre Pineau and Jean-Paul Vinson, as well as Monique Dechambre for her active participation to the campaigns. They also wish to thank the staff of the SAFIRE team who operated the ATR42 aircraft. The development and operation of the KuROS radar was funded by the French space agency CNES (Centre National d'Etudes Spatiales). The Lion buoy data have been provided by Meteo-France in the context of the HyMeX project. 


\section{REFERENCES}

Caudal, G., E. Dinnat, and J. Boutin, Absolute calibration of radar altimeters : Consistency with electromagnetic modeling, J. Atm. Ocean. Technology, Vol. 22, 771-781, 2005.

Chapron, B., F. Collard, and F. Ardhuin, Direct measurements of ocean surface velocity from space : Interpretation and validation, J. Geophys. Res., 110, C07008, doi :10.1029/2004JC002809, 2005.

Drobinski P., V. Ducrocq, P. Alpert, E. Anagnostou, K. Béranger, M. Borga, I. Braud, A. Chanzy, S. Davolio, G. Delrieu, C. Estournel, N. Filali, Boubrahmi, J. Font, V. Grubisic, S. Gualdi, V. Homar, B. Ivancan-Picek, C. Kottmeier, V. Kotroni, K. Lagouvardos, P. Lionello, M. C. Llasat, W. Ludwig, C. Lutoff, A. Mariotti, E. Richard, R. Romero, R. Rotunno, O. Roussot, I. Ruin, S. Somot, I. Taupier-Letage, J. Tintore, R. Uijlenhoet, H. Wernli, HyMeX, a 10-year Multidisciplinary Program on the Mediterranean Water Cycle, Bull. Amer. Meteorol. Soc., doi: http://dx.doi.org/10.1175/BAMS-D-12-00242.1 in press, 2013.

Cavaleri, L., Wave modeling : where to go in the future, Bull. Amer. Meteor. Soc.,87, 207-214, 2006.

Engen, G., and H. Johnsen, SAR-Ocean wave inversion using image cross spectra, IEEE Trans. Geosci. Rem. Sens., Vol. 33, No. 4,1995.

Freilich M. H., and B. A. Vanhoff, The relationship between winds, surface roughness, and radar backscatter at low incidence angles from TRMM Precipitation Radar measurements, Journal of Atmospheric and Oceanic Technology, Vol. 20, 549-562, 2003.

Fuchs, B., and J. J. Fuchs, Optimal narrow beam low sidelobe synthesis for arbitrary arrays, IEEE Trans. on Antennas and Propagation, Vol. 58, 2130-2135, 2010.

Gonzalez F. I., R. C. Beal, W. E. Brown, P. S. DeLeonibus, J. W. Sherman III, J. F. R. Gower, D. Lichy, D. B. Ross, C. L. Rufenach, and R. A. Shuchman, Seasat synthetic aperture radar: ocean wave detection capabilities, Science, Vol. 204, 1418-1421, 1979.

Hauser D., G. Caudal, G. J. Rijckenberg, D. Vidal-Madjar, G. Laurent, and P. Lancelin, RESSAC : A new airborne FM/CW radar ocean wave spectrometer, IEEE Transactions on Geoscience and Remote Sensing, 30(5), 981-995, 1992.

Hauser, D., and G. Caudal, Combined analysis of the radar cross-section modulation due to the long ocean waves around 14 and $34^{\circ}$ incidence : implication for the hydrodynamic modulation, $J$. Geophys. Res., 101(C11), 25833-25846, 1996.

Hauser D., T. Podvin, M. Dechambre, R. Valentin, G. Caudal, J.-F. Daloze, STORM : A new airborne polarimetric real-aperture radar for Earth observations, in Proceedings of POLINSAR Workshop (Workshop on Applications of SAR Polarimetry and Polarimetric Interferometry), ESA SP-529, Frascati, Italy, 14-16 january 2003. 
Hauser D., C. Tison, J.-M. Lefevre, J. Lambin, T.Amiot, L. Aouf, F. Collard, and P. Castillan, Measuring ocean waves from space: Objectives and characteristics of the China-France Oceanography SATellite (CFOSAT), Proceedings of the ASME 2010 29th International Conference on Ocean, Offshore and Arctic engineering, Volume 4, Shanghai, China, june 6-11, 2010, pp. 85-90, doi : 10.1115/OMAE2010-20184, 2010.

Jackson F. C., W. T. Walton, and P. L. Baker, Aircraft and satellite measurement of ocean wave directional spectra using scanning-beam microwave radars, J. Geophys. Res., Vol. 90, 987-1004, $1985 \mathrm{a}$.

Jackson F. C., W. T. Walton, and C. Y. Peng, A comparison of in situ and airborne radar observations of ocean wave directionality, J. Geophys. Res., Vol. 90, 1005-1018, 1985 b.

Petterson H., H. C. Graber, D. Hauser, C. Quentin, K. K. Kahma, W. M. Drennan, and M. A. Donelan, Directional wave measurements from three wave sensors during the FETCH experiment, J. Geophys. Res., 108(C3), 8061, doi:10.1029/2001JC001164, 2003.

Plant W. J., W. C. Keller, and K. Hayes, Simultaneous measurements of ocean winds and waves with an airborne coherent real aperture radar, Journal of Atmospheric and Oceanic Technology, Vol. 22, 832-846, 2005.

Thompson, D. R., B. L. Gotwols, and W. C. Keller, A comparison of Ku-Band Doppler measurements at $20^{\circ}$ incidence with predictions from a time-dependent scattering model, $J$. Geophys. Res., 96, No. C3, 4947-4955, 1991.

Tran N., Contribution à l'étude des diffusiomètres NSCAT et ERS-2 par modélisation neuronale. Influence de la hauteur des vagues sur le signal diffusiométrique, $\mathrm{PhD}$ dissertation, Univ. Pierre et Marie Curie, Paris, France, 1999.

Tran N., B. Chapron, and D. Vandemark, Effect of long waves on Ku-band ocean radar backscatter at low incidence angles using TRMM and altimeter data, IEEE Geoscience and Remote Sensing Letters, Vol. 4, No. 4, 542-546, 2007.

Walsh E. J., D. W. Hanckock, D. E. Hines, R. N. Swift, and J. F. Scott, Directional wave spectra measured with the surface contour radar, J. Phys. Oceanogr., Vol. 15, 566-592, 1985.

Wentz F. J., and D. K. Smith, A model function for the ocean-normalized radar cross section at $14 \mathrm{GHz}$ derived from NSCAT observations, J. Geophys. Res., 104, No. C5, 11,499-11,514, 1999.

WISE Group (Cavaleri et al) : Wave modelling the state of the art 1$]$. Progress in Oceanography Volume 75, Issue 4, pp. 603-674, 2007.

Zrnic, D. S., Spectral moment estimates from correlated pulse pairs, IEEE Trans. Aerosp. Electron. Syst., Vol. AES-13, 344-354, 1977. 
Table 1. Major parameters of the KuROS radar

\begin{tabular}{ll}
\hline Parameter & Value \\
\hline Frequency & $13.5 \mathrm{GHz}$ \\
Transmitted power & $11 \mathrm{~W}$ \\
LI antenna & $14^{\circ}$ boresight incidence angle; gain=18.5dB; \\
& $18.5^{\circ}$ elevation by $8.6^{\circ}$ azimuth one-way beamwidth, HH polar \\
& $40^{\circ}$ boresight incidence angle \\
MI antenna & $21^{\circ}$ elevation by $8^{\circ}$ azimuth beamwidth; gain=17.5dB (HH polar) \\
& $17^{\circ}$ elevation by $8^{\circ}$ azimuth beamwidth; gain=18dB (VV polar) \\
SNR ratio ( 1 pulse) & LI antenna: $11.3 \mathrm{~dB} ;$ MI antenna: $-5.4 \mathrm{~dB}$ \\
Antenna rotation speed & 2.4 to $4.6 \mathrm{rotations} /$ minute (tunable) \\
Aircraft speed & 90 to $110 \mathrm{~m} / \mathrm{s}$
\end{tabular}


Table 2. Radar parameters for the different modes of operation. $\mathrm{H}$ is the approximative flight altitude (above the surface). PRI is the Pulse Repetition Interval. $T_{p}$ is the Pulse duration. $T_{\text {rep }}$ is the replica duration. Frequency Range is the frequency band of the chirp generated by the transmitter. $\mathrm{F}_{\text {repmax }}$ is the highest frequency of the replica. Analysis band $\mathrm{B}_{\mathrm{A}}=\mathrm{F}_{\text {repmax }}-\mathrm{F}_{\text {emax }}$ is the frequency band after deramping stage. $\mathrm{N}_{\text {real }}$ is the number of points after decimation stage. $\mathrm{N}_{\mathrm{FFT}}$ corresponds to the power of 2 number of points for FFT processing by extending the number of points by zero padding. SNR is given for one pulse, without integration.

\begin{tabular}{|c|c|c|c|c|c|c|c|c|c|c|}
\hline antenna & $\begin{array}{c}\mathbf{H} \\
(\mathbf{m})\end{array}$ & $\begin{array}{l}\text { PRI } \\
(\mu s)\end{array}$ & $\begin{array}{c}\mathbf{T}_{\mathrm{p}} \\
(\boldsymbol{\mu})\end{array}$ & $\begin{array}{l}T_{\text {rep }} \\
(\mu \mathrm{s})\end{array}$ & $\begin{array}{c}\text { Frequency } \\
\text { Range } \\
{\left[\mathrm{F}_{\text {emin }}-\mathbf{F}_{\text {emax }}\right]} \\
(\mathrm{MHz})\end{array}$ & $\begin{array}{c}\text { Frepmax } \\
(\mathrm{MHz})\end{array}$ & $\begin{array}{c}\text { Analysis } \\
\text { band } \\
\text { B }_{\mathrm{A}}(\mathrm{MHz}) \\
\end{array}$ & $\mathbf{N}_{\text {real }}$ & $\mathbf{N}_{\mathrm{FFT}}$ & $\begin{array}{l}\text { SNR } \\
\text { (dB) }\end{array}$ \\
\hline LI & 3000 & 43.5 & 17 & 22.54 & $25-125$ & 157.59 & 32.59 & 1352 & 2048 & 11.3 \\
\hline LI & 2000 & 28.5 & 10.33 & 15.92 & $25-125$ & 179.11 & 54.11 & 955 & 1024 & 16.6 \\
\hline LI & 1000 & 16.5 & 5.66 & 8.56 & $25-125$ & 176.24 & 51.24 & 514 & 512 & 25.6 \\
\hline LI & 450 & 7.0 & 2 & 3.05 & $25-125$ & 177.50 & 52.50 & 183 & 256 & 36.0 \\
\hline MI & 3000 & 53.5 & 17 & 34.45 & $30-60$ & 90.79 & 30.79 & 2067 & 2048 & -5.4 \\
\hline MI & 2000 & 37.0 & 10.33 & 24.48 & $30-60$ & 101.09 & 41.09 & 1469 & 2048 & -0.1 \\
\hline MI & 1000 & 22.0 & 5.66 & 13.4 & $30-60$ & 101.02 & 41.02 & 804 & 1024 & 8.9 \\
\hline MI & 450 & 12.0 & 2 & 5.09 & $30-60$ & 106.35 & 46.35 & 305 & 512 & 19.3 \\
\hline
\end{tabular}


Table 3. Theoretical errors on the estimation of the backscattering coefficient for the LI and MI antennae in the middle of antenna footprint, for the $3000 \mathrm{~m}$ altitude modes of Table $2 . \mathrm{N}_{P P}$ $\left(=T_{I} / P R I\right)$ is the number of integrated pulse pairs within the integration time $T_{I}$.

\begin{tabular}{|c|c|c|c|c|}
\hline Coherent integration time $T_{I}$ & 1 PRI & $1 \mathrm{~ms}$ & $30 \mathrm{~ms}$ & $100 \mathrm{~ms}$ \\
\hline $\mathrm{N}_{\mathrm{PP}}(\mathrm{LI}$ antenna: $\mathrm{PRI}=43.5 \mu \mathrm{s})$ & 1 & 23 & 690 & 2300 \\
\hline SNR (dB) (LI antenna) & 11.3 & 18.1 & 25.5 & 28.1 \\
\hline$\delta \sigma^{\circ}(\mathrm{dB})(\mathrm{LI}$ antenna $)$ & & 0.83 & 0.16 & 0.08 \\
\hline $\mathrm{N}_{\mathrm{PP}}(\mathrm{MI}$ antenna: $\mathrm{PRI}=53.5 \mu \mathrm{s})$ & 1 & 18 & 540 & 1800 \\
\hline SNR (dB) (MI antenna) & -5.4 & 0.9 & 8.3 & 10.9 \\
\hline$\delta \sigma^{\circ}(\mathrm{dB})$ (MI antenna) & & 1.55 & 0.19 & 0.1 \\
\hline
\end{tabular}


Table 4. List of KuROS data during HyMeX campaign. The wave direction is calculated at the peak of the omnidirectional sea wave spectrum, from the triaxial instrument at the Lion buoy. When 2 values of wind and wave data are indicated, it means that we have considered 2 successive buoy measurements (1D spectra and directional data are obtained every hour and every 3 hours, respectively). Both flights performed in Brittany refer to PROTEVS campaign.

\begin{tabular}{|c|c|c|c|c|c|c|c|c|}
\hline $\begin{array}{c}\text { Date } \\
\text { (DD/M/YY) }\end{array}$ & $\begin{array}{c}\text { Flight } \\
\text { num- } \\
\text { ber }\end{array}$ & $\begin{array}{l}\text { Time of } \\
\text { KuROS } \\
\text { acquisition } \\
\text { at } 2000 \text { or } \\
3000 \mathrm{~m} \\
\text { flight level } \\
\text { (UTC) }\end{array}$ & $\begin{array}{l}\text { Meteorological } \\
\text { situation }\end{array}$ & $\begin{array}{l}\text { Wind } \\
\text { speed } \\
(\mathrm{m} / \mathrm{s})\end{array}$ & $\begin{array}{l}\text { Wind } \\
\text { direc- } \\
\text { tion } \\
(\% / N)\end{array}$ & $\begin{array}{l}\text { Signifi- } \\
\text { cant } \\
\text { wave } \\
\text { height } \\
\text { (m) }\end{array}$ & $\begin{array}{l}\text { Wave } \\
\text { Peak } \\
\text { fre- } \\
\text { quency } \\
\text { (Hz) }\end{array}$ & $\begin{array}{l}\text { Wave } \\
\text { peak } \\
\text { direction } \\
\text { (from } \\
\% / N \text { ) }\end{array}$ \\
\hline $6 / 2 / 13$ & 4 & $\begin{array}{l}13: 48- \\
17: 42\end{array}$ & Tramontane/Mistral & $\begin{array}{c}13.4- \\
13.9\end{array}$ & $280-290$ & $2.5-3.1$ & 0.135 & 310 \\
\hline $11 / 2 / 13$ & 6 & $11: 11-13: 50$ & $\begin{array}{l}\text { Brittany - Swell } \\
\text { form Northwest }\end{array}$ & & & 6.8 & 0.075 & 290 \\
\hline $11 / 2 / 13$ & 7 & $\begin{array}{l}15: 53- \\
16: 59\end{array}$ & $\begin{array}{l}\text { Brittany - Swell } \\
\text { form Northwest }\end{array}$ & & & 6.8 & 0.075 & 290 \\
\hline $13 / 2 / 13$ & 9 & $\begin{array}{c}13: 25- \\
16: 40\end{array}$ & Tramontane/Mistral & 17.0 & $320-330$ & $4.7-4.9$ & 0.111 & 330 \\
\hline $14 / 2 / 13$ & 10 & $\begin{array}{c}07: 53- \\
13: 00\end{array}$ & $\begin{array}{c}\text { Tramontane/Mistral } \\
\text { decreasing }\end{array}$ & $\begin{array}{c}10.8- \\
11.8\end{array}$ & $340-350$ & $2.4-2.7$ & 0.146 & 360 \\
\hline $15 / 2 / 13$ & 11 & $\begin{array}{c}10: 33- \\
14: 34\end{array}$ & Tramontane/Mistral & $\begin{array}{l}12.3- \\
13.4\end{array}$ & $320-330$ & $3.0-3.2$ & 0.135 & 310 \\
\hline $23 / 2 / 13$ & 13 & $\begin{array}{l}14: 05- \\
14: 36\end{array}$ & Tramontane/Mistral & 17.5 & 320 & 5.4 & 0.0996 & 300 \\
\hline $1 / 3 / 13$ & 14 & $\begin{array}{c}11: 52 \text { à } \\
14: 32\end{array}$ & $\begin{array}{l}\text { Easterley wind } \\
\text { conditions }\end{array}$ & $\begin{array}{l}14.9- \\
15.4\end{array}$ & 70 & $4.5-4.9$ & 0.111 & 90 \\
\hline $2 / 3 / 13$ & 15 & $\begin{array}{c}06: 13 \text { à } \\
09: 08\end{array}$ & $\begin{array}{c}\text { Tramontane/Mistral } \\
\text { decreasing }\end{array}$ & $\begin{array}{l}10.8- \\
12.3\end{array}$ & $340-360$ & $2.6-2.7$ & $\begin{array}{c}0.111- \\
0.123\end{array}$ & $5-35$ \\
\hline $4 / 3 / 13$ & 16 & $\begin{array}{l}14: 30 \text { à } \\
18: 15\end{array}$ & $\begin{array}{l}\text { Easterley wind } \\
\text { conditions }\end{array}$ & $9.8-10.3$ & 120 & $1.4-1.5$ & $\begin{array}{c}0.193- \\
0.217\end{array}$ & 100 \\
\hline $05 / 03 / 13$ & 17 & $\begin{array}{c}\text { 12:45 à 15: } \\
38\end{array}$ & $\begin{array}{l}\text { Easterley wind } \\
\text { conditions }\end{array}$ & $\begin{array}{c}13.9- \\
14.4\end{array}$ & 100 & 4.7 & 0.111 & $90-100$ \\
\hline $06 / 03 / 13$ & 18 & $\begin{array}{l}11: 47 \text { à } \\
14: 22\end{array}$ & $\begin{array}{l}\text { Easterley wind } \\
\text { conditions, } 2 \text { hours } \\
\text { after wind drop } \\
\text { rotating }\end{array}$ & $8.7-9.8$ & 120 & $5.2-5.3$ & 0.088 & 65 \\
\hline $13 / 03 / 13$ & 20 & 14:40-18:03 & $\begin{array}{c}\text { Tramontane/Mistral } \\
\text { increasing period }\end{array}$ & $\begin{array}{l}16.4- \\
18.0\end{array}$ & 320 & $3.3-4.0$ & $\begin{array}{c}0.111- \\
0.123\end{array}$ & 310 \\
\hline $14 / 03 / 13$ & 21 & $13: 55-17: 30$ & Tramontane/Mistral & 19.5 & 300 & $6.0-6.1$ & 0.0996 & 310 \\
\hline $15 / 03 / 13$ & 22 & 07:13-10:30 & Tramontane/Mistral & $\begin{array}{l}18.0- \\
19.0\end{array}$ & 320 & 5.4-6.1 & 0.111 & $310-330$ \\
\hline
\end{tabular}




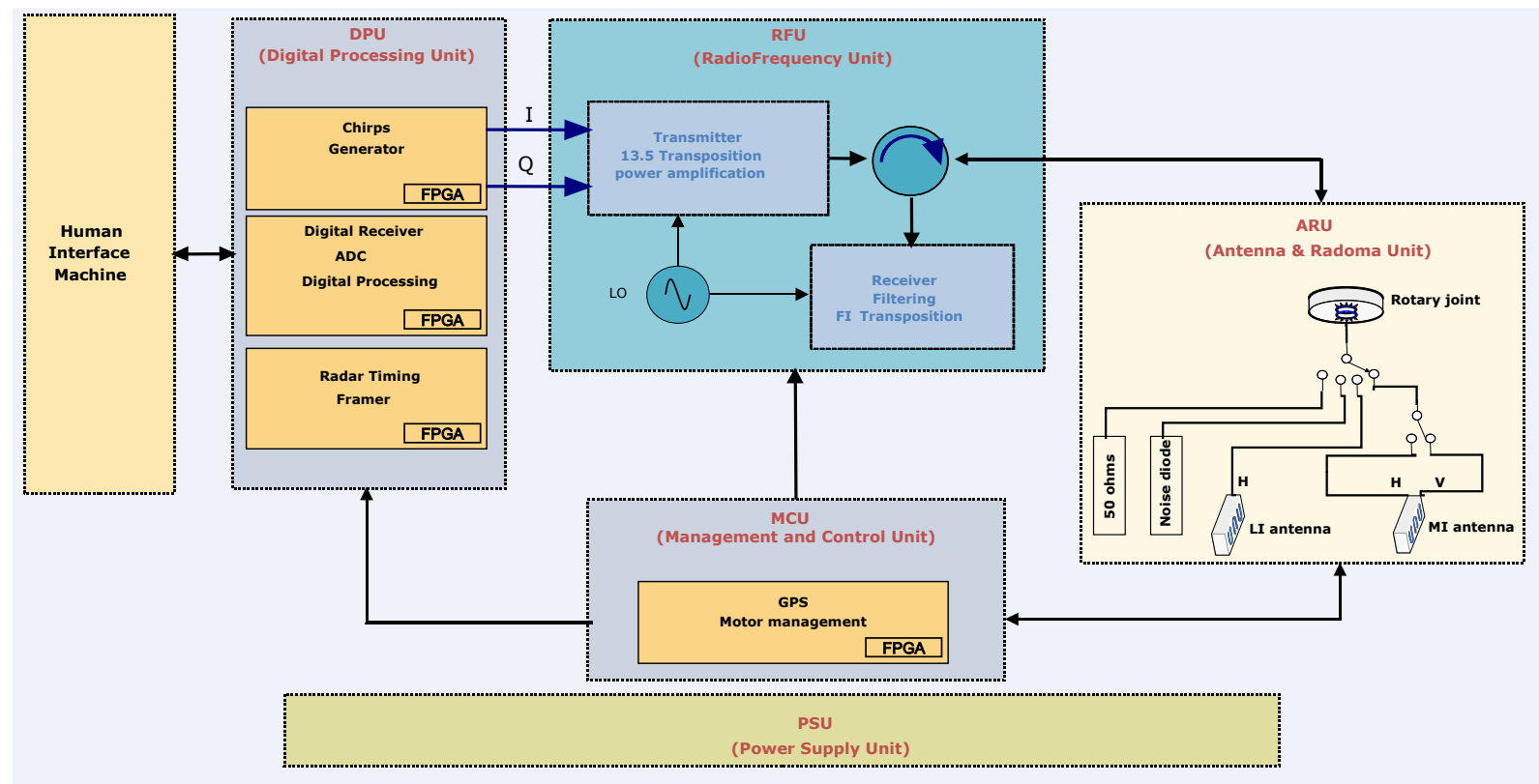

Figure 1. Block diagram of the KuROS instrument 


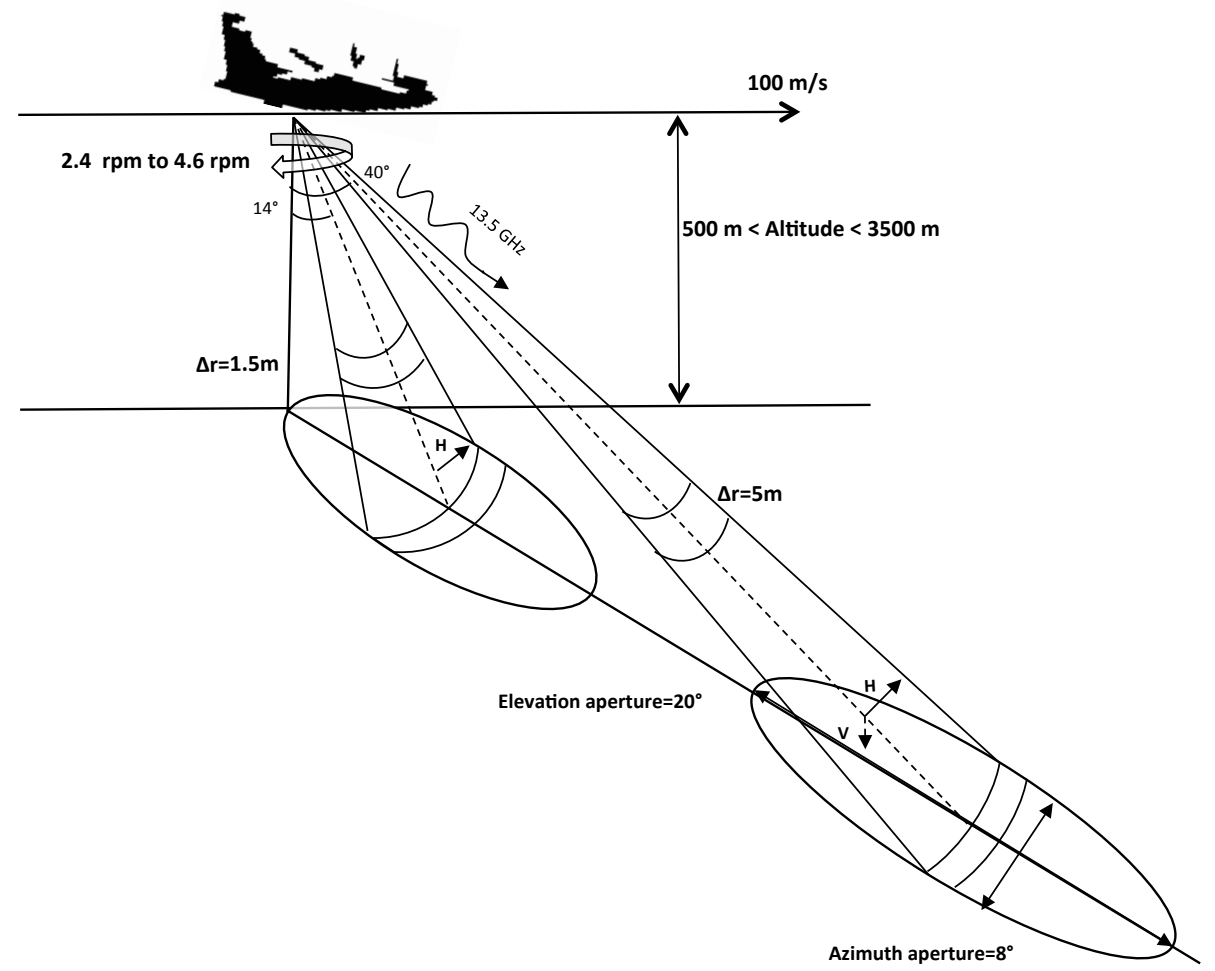

Figure 2. Geometry of observation, showing the footprints of both LI and MI antennae. 


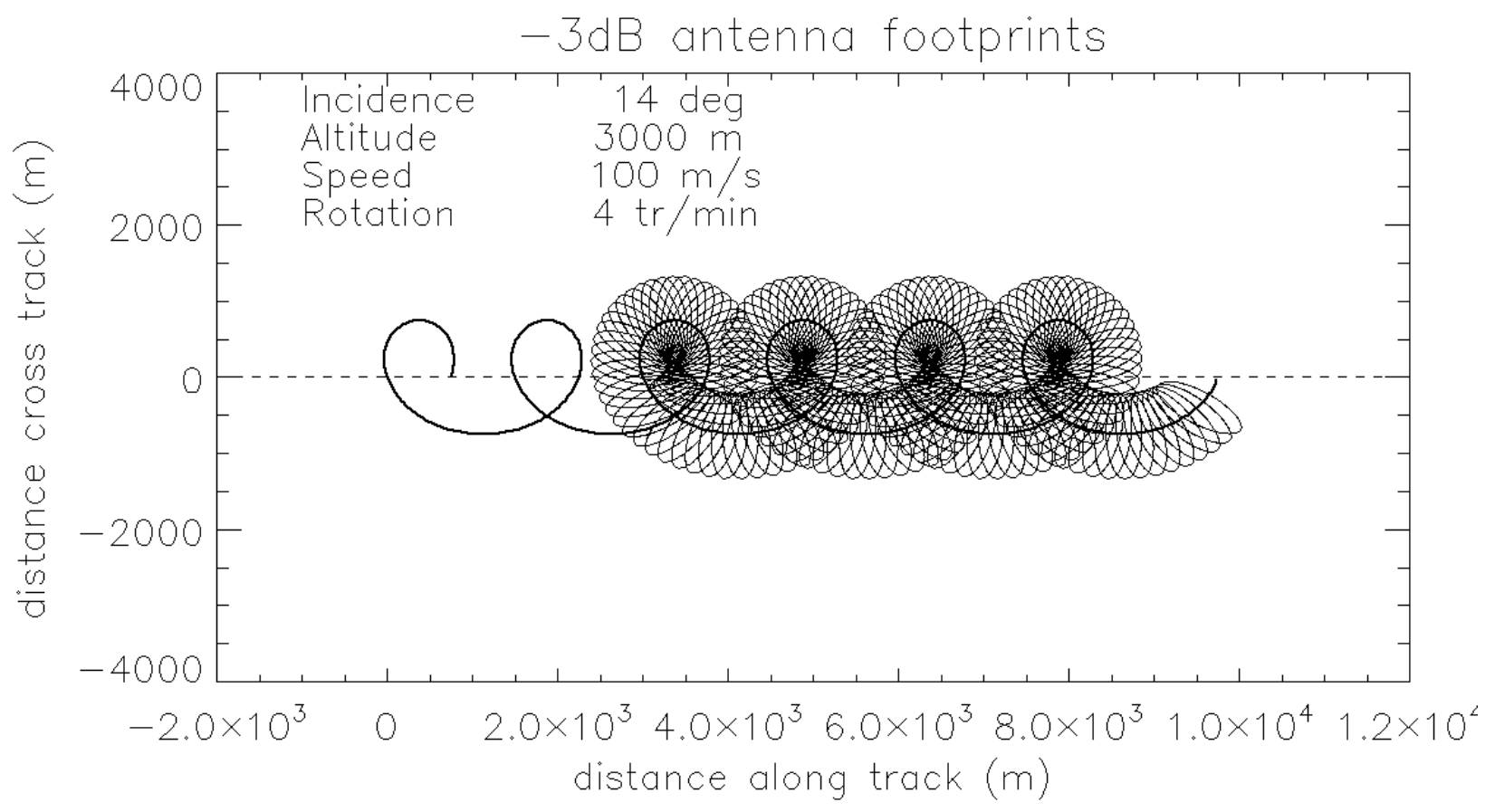

Figure 3. LI antenna footprint along the aircraft track every $300 \mathrm{~ms}$ from altitude $3000 \mathrm{~m}$, for a rate of 4 antenna rotations per minute, and an aircraft velocity of $100 \mathrm{~m} / \mathrm{s}$. The cycloid describing the trajectory of the footprint of the beam axis is also plotted. 


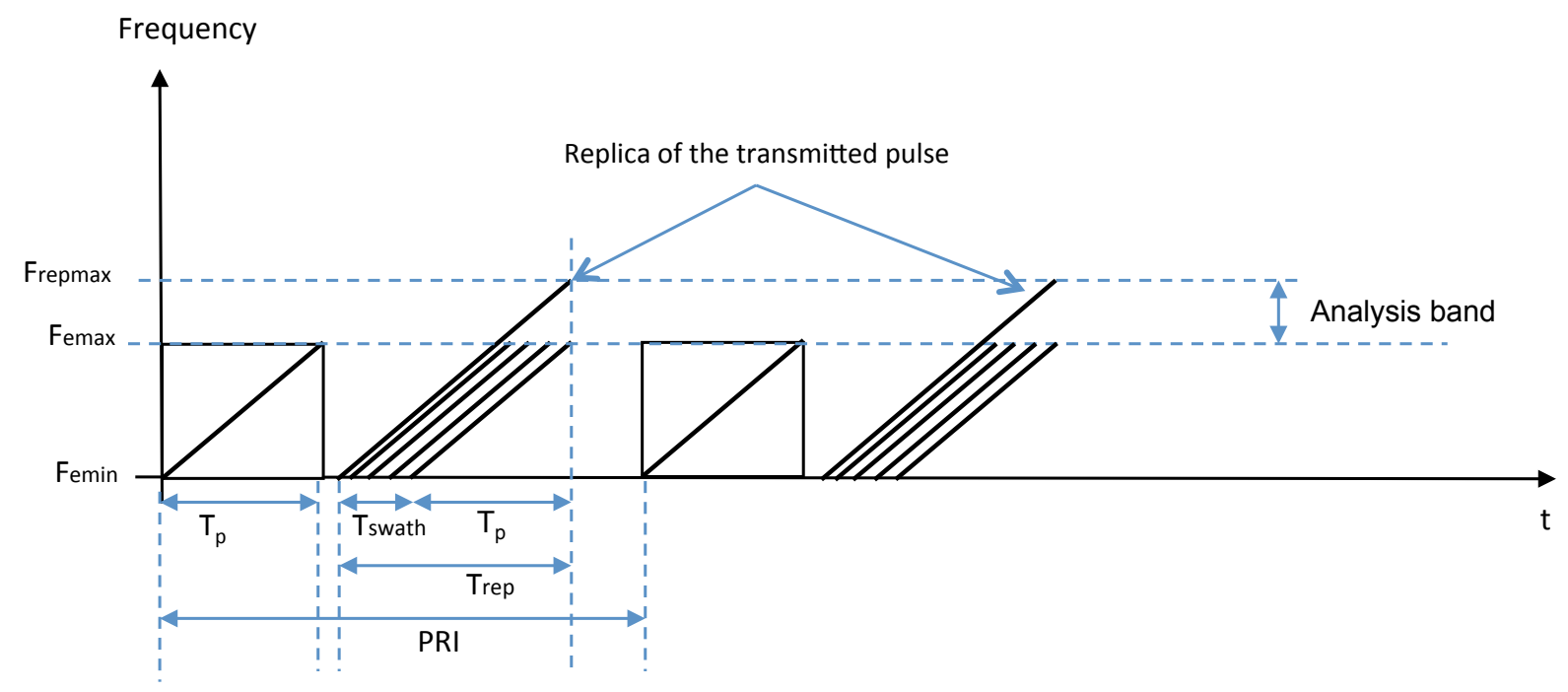

Figure 4. Time-frequency diagram of the transmitted pulses 


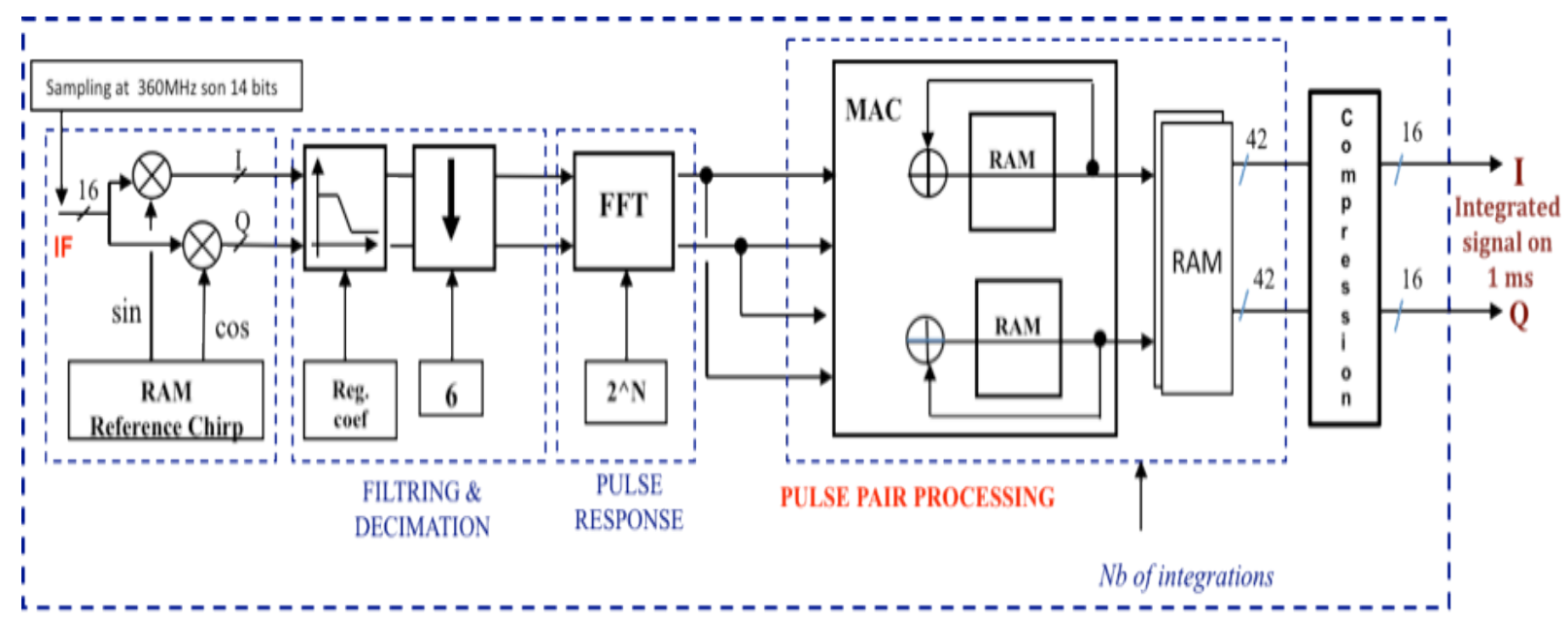

Figure 5. Schematic diagram of the radar digital processing unit (DPU)

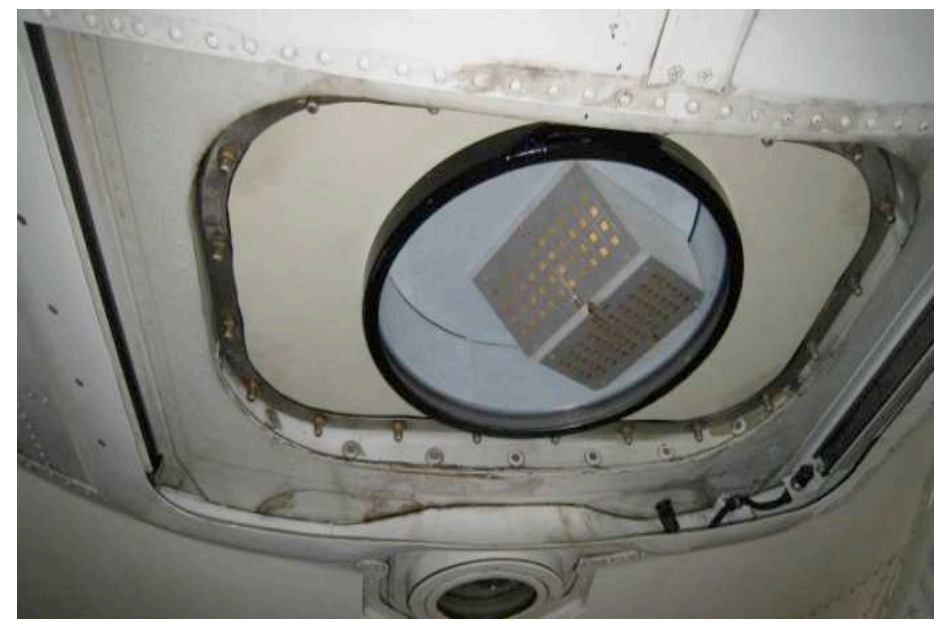

Figure 6. External view of both antennae aiming through the quartz windows 


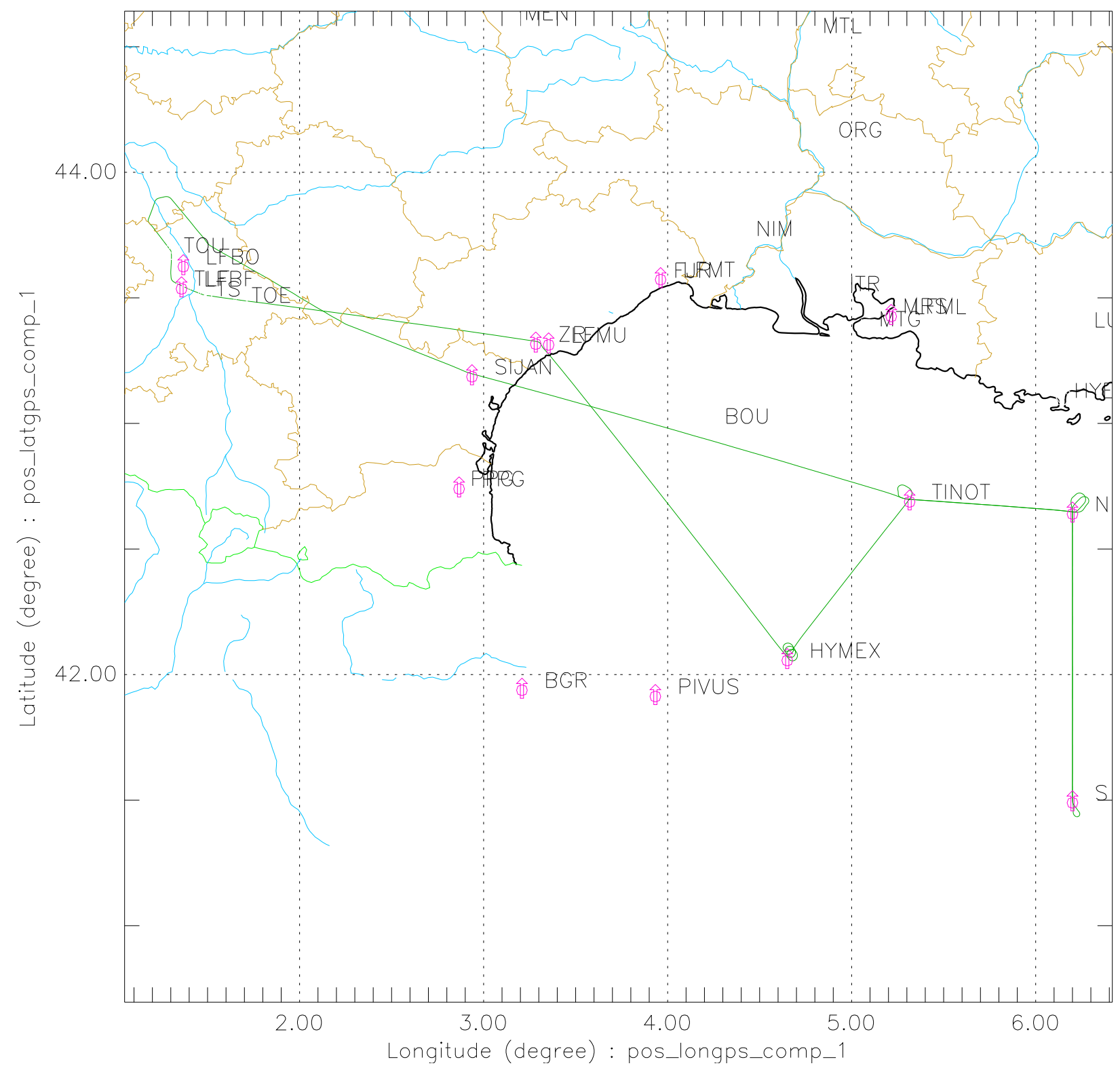

Figure 7. Example of flight plan (in green line) during the SOP\#2 of the HyMeX campaign (flight number 18), provided by the SAFIRE team. The meteo-oceanic Lion buoy was moored at point labelled HyMeX in the figure. 


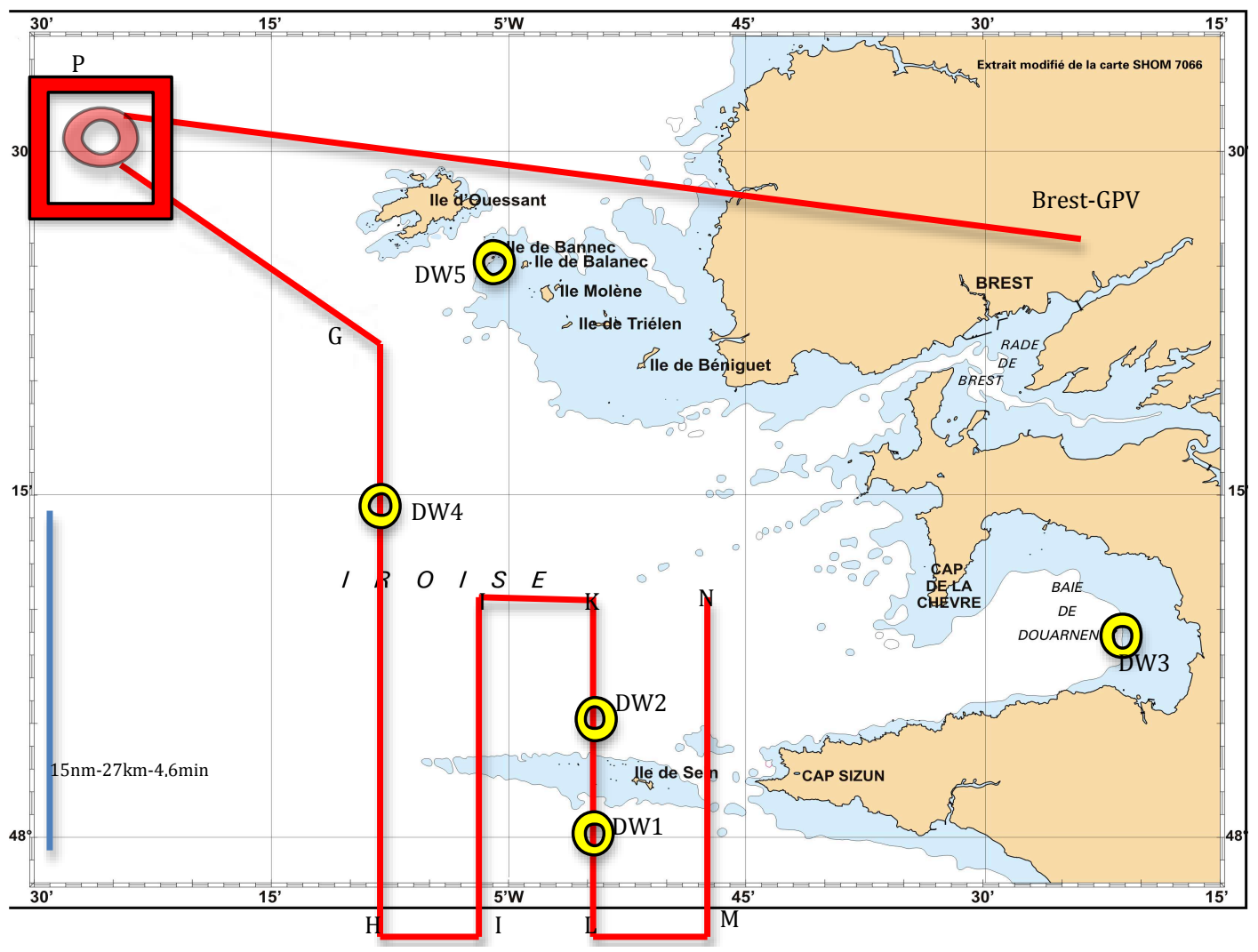

Figure 8. ATR42 Flight plan with KuROS during the PROTEVS campaign. The red pattern has been overflown three times (once at $2000 \mathrm{~m}$ around 12:00 UT, and twice at $3000 \mathrm{~m}$ flight level around 13:00 UT and 16:30 UT). 
KuROS 3-C reflector $\mathrm{F} 12$

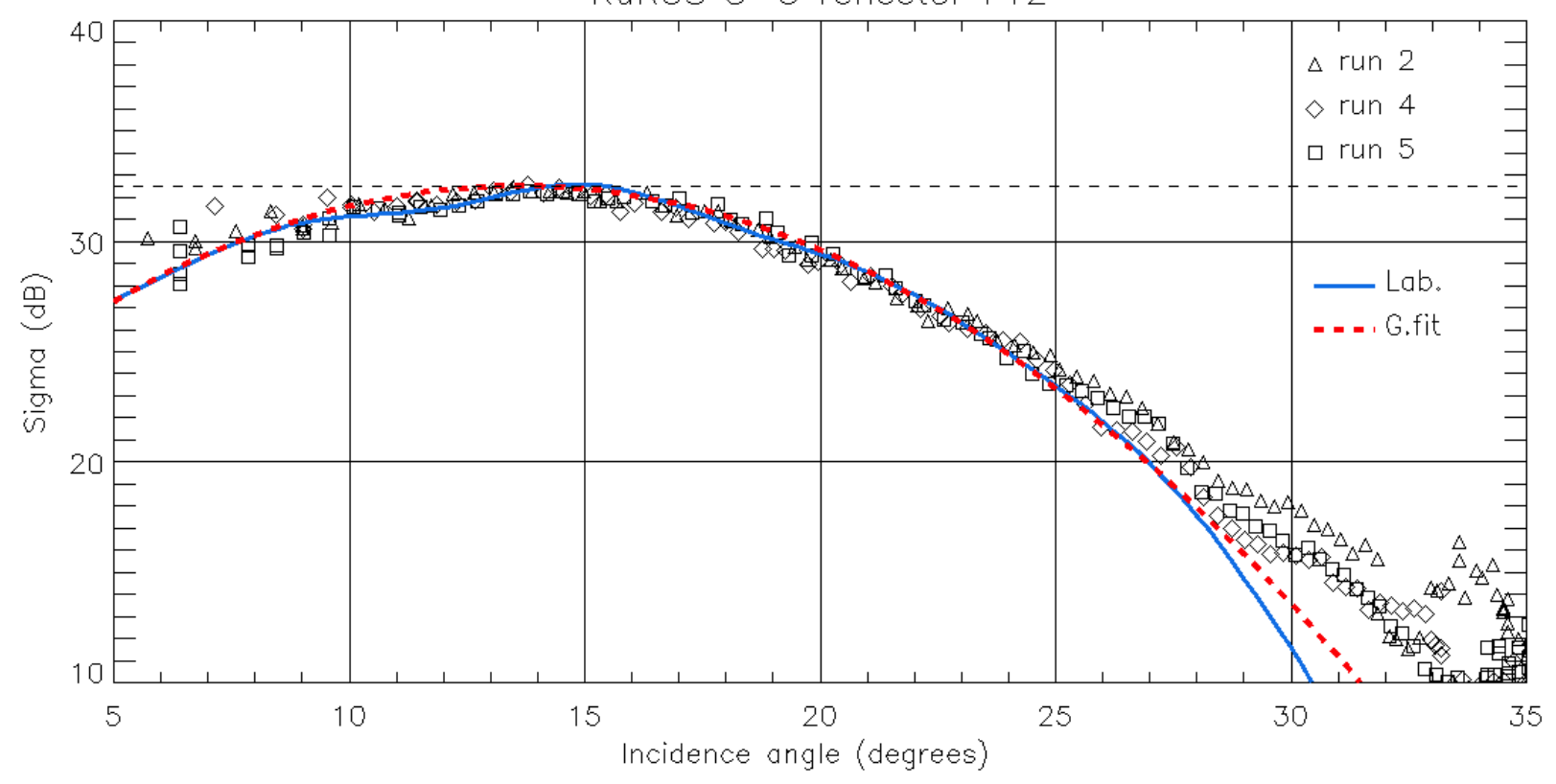

Figure 9. Results from the LI antenna absolute calibration overflights on corner reflectors. Each symbol (triangle, diamond, square) corresponds to one of the 3 successful overflights. For each overflight, only the reflector located the closest to the flight track (i. e., yielding the highest power backscatter signature) is displayed. Antenna radiation pattern obtained from the anechoic chamber measurements (blue line), and its Gaussian fit (red dashed line), with maxima coinciding with the $32.5 \mathrm{dBm}^{2}$ radar cross section of the triedral reflectors at boresight. 


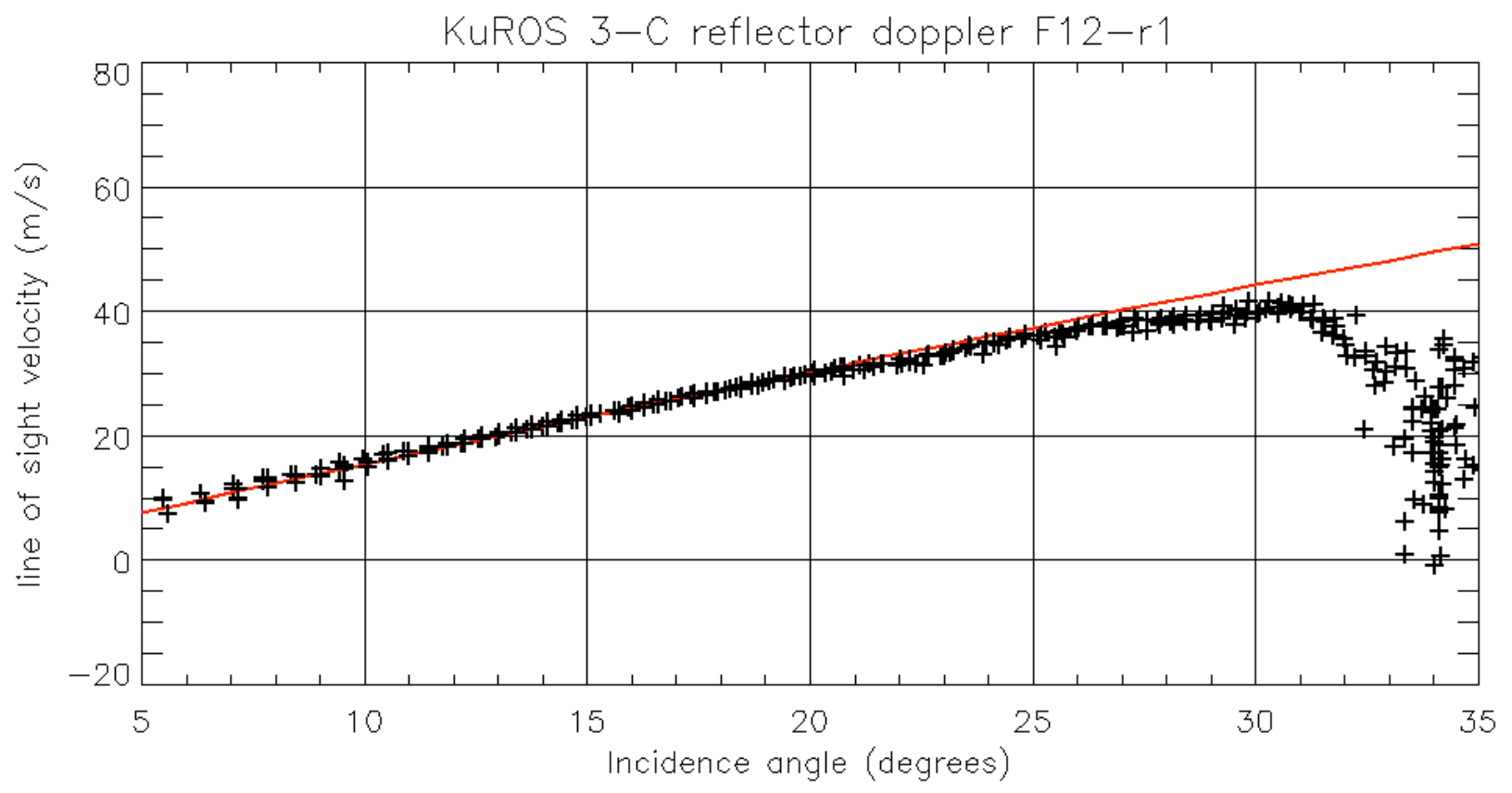

Figure 10. Doppler velocity obtained by the radar from one overflight of the trihedral reflectors. Only data from the three most centered trihedrals (those yielding the highest power patterns) are shown ( + signs). The red solid line is the theoretical radial velocity (proportional to $\sin \theta)$ deduced from the aircraft inertial navigation system. 


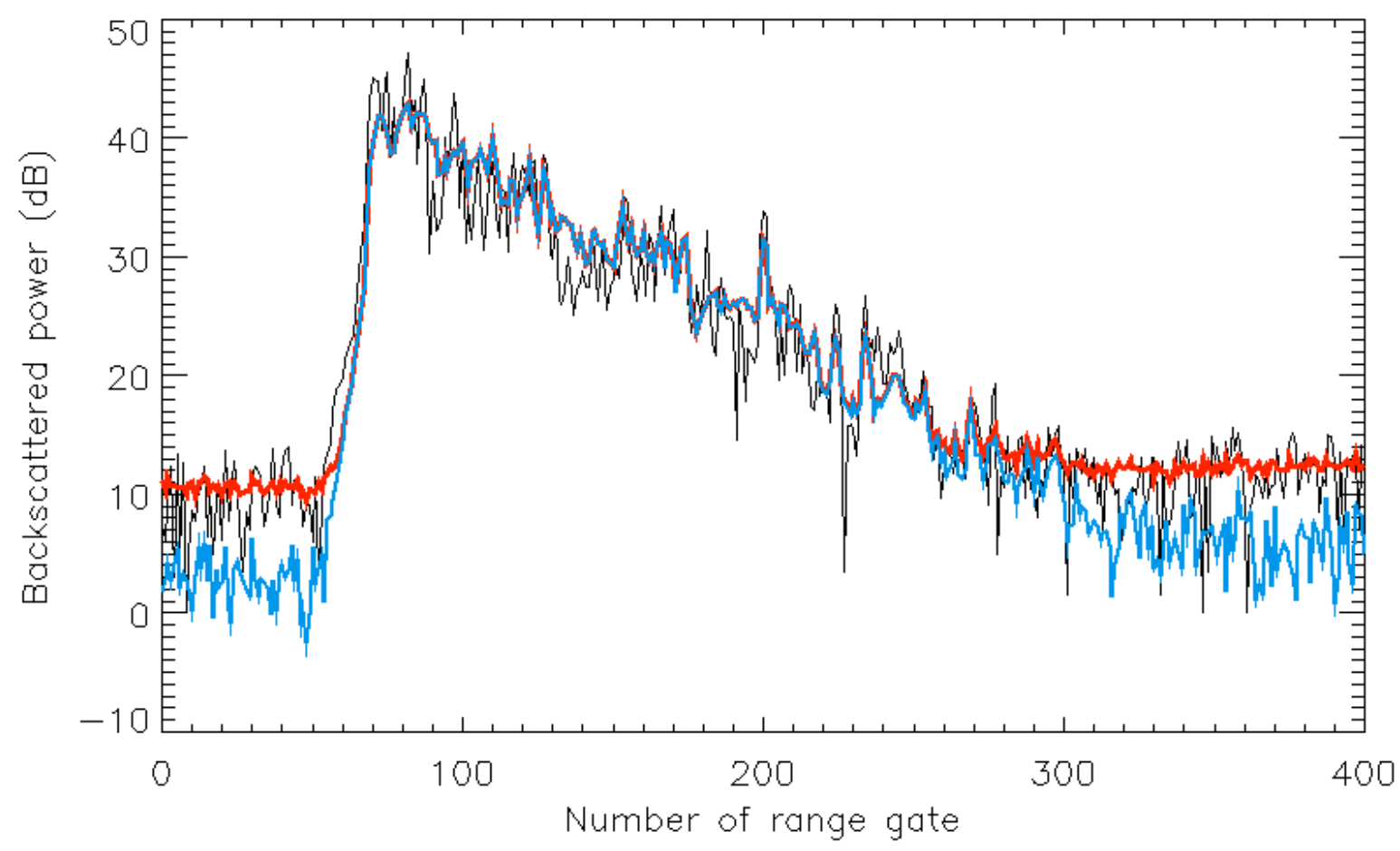

Figure 11. Example of the radar power profile obtained over the sea at $2000 \mathrm{~m}$ altitude. Black line : coherent real-time integration over $1 \mathrm{~ms}$; blue line : coherent post-integration over $33 \mathrm{~ms}$; red line : incoherent post-integration over $33 \mathrm{~ms}$. 


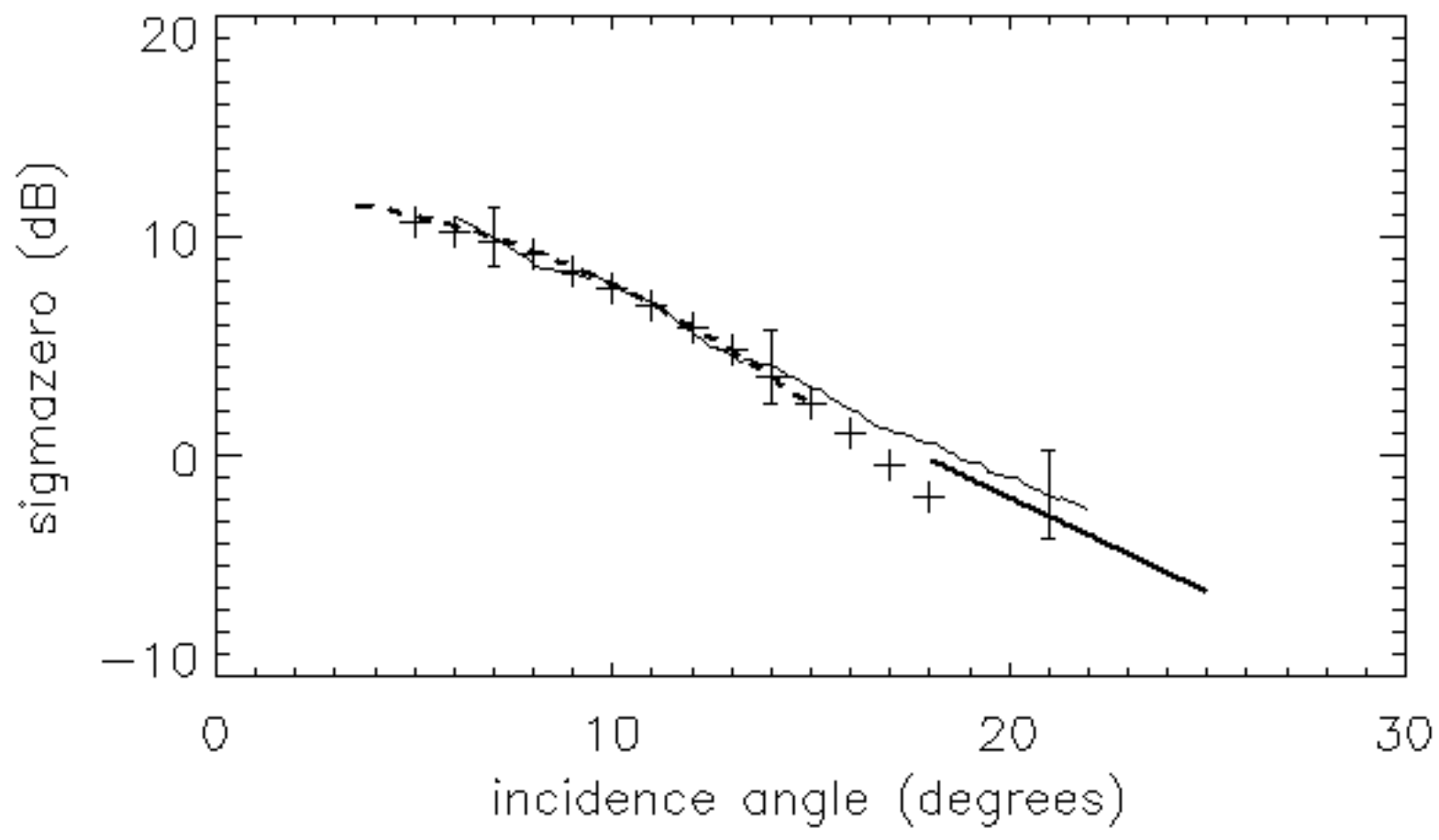

Figure 12. Normalized radar cross section $\sigma^{\circ}$ averaged over the azimuthal directions, as a function of incidence angle. The error bars indicate the standard deviation of the data over an incidence angle interval of $1^{\circ}$. Thin solid line : data obtained from KuROS on 6 march 2013 (flight 18, $12: 26: 31$ ) near the Lion buoy. Dashed line: Freilich and Vanhoff's (2003) model derived from TRMM PR data. + signs : quadratic fit to TRMM data involving U and Hs. thick solid line: Wentz and Smith's (1999) model derived from NSCAT data. The wind speed is $\mathrm{U}=9 \mathrm{~m} / \mathrm{s}$ and significant wave height is $\mathrm{Hs}=5.3 \mathrm{~m}$. 


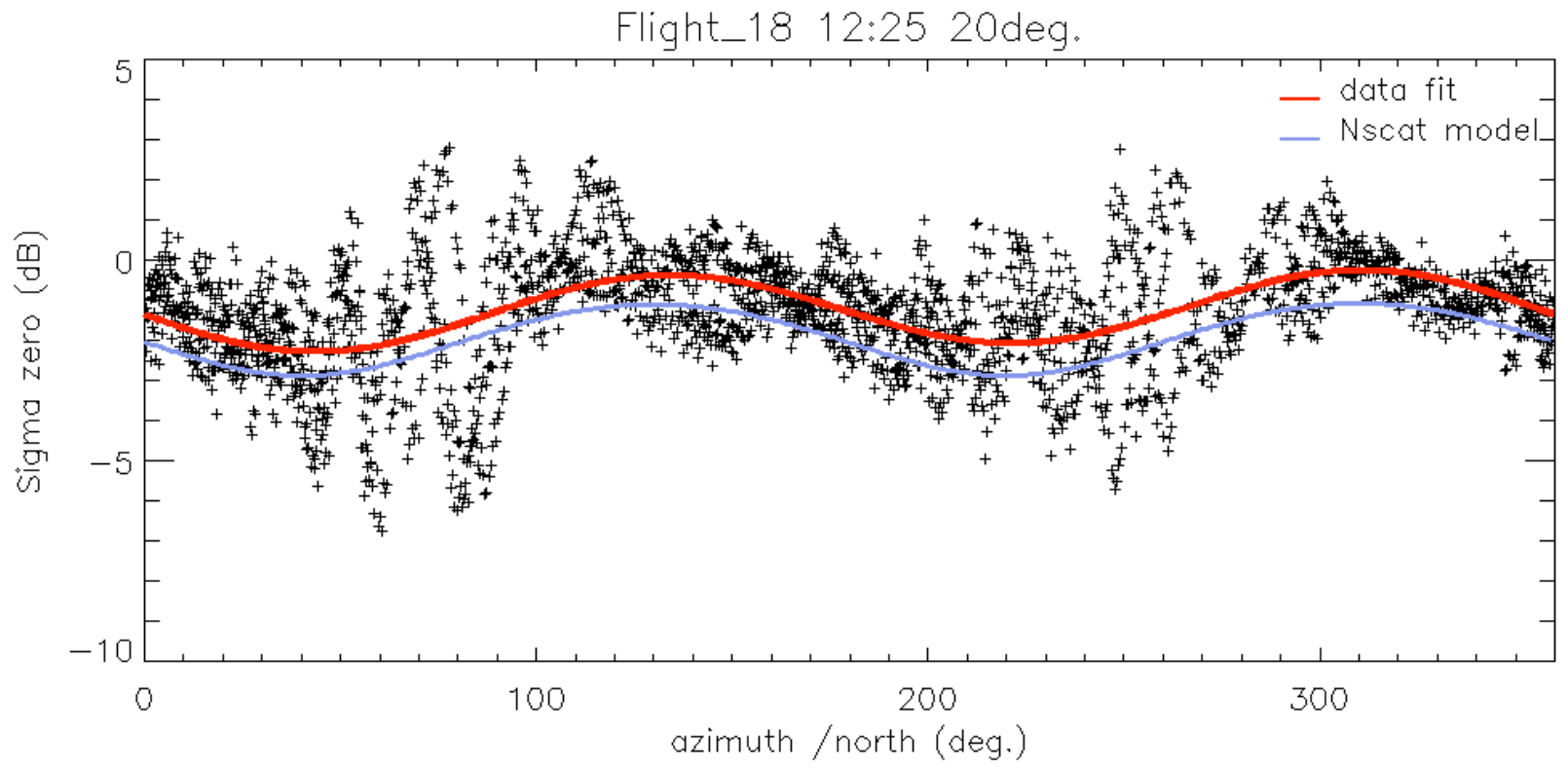

Figure 13. Normalized radar cross section $\sigma^{\circ}$ as a function of azimuth, for an incidence $\theta=20^{\circ}$, for the case shown in Figure 12. Crosses: data obtained from KuROS. Red line : least-square fit to the data involving two harmonics. The large scatter $( \pm 4 \mathrm{~dB})$ of the data around the fitted line is due to the presence of the long sea waves. Blue line: Wentz and Smith's (1999) empirical model derived from NSCAT data. 


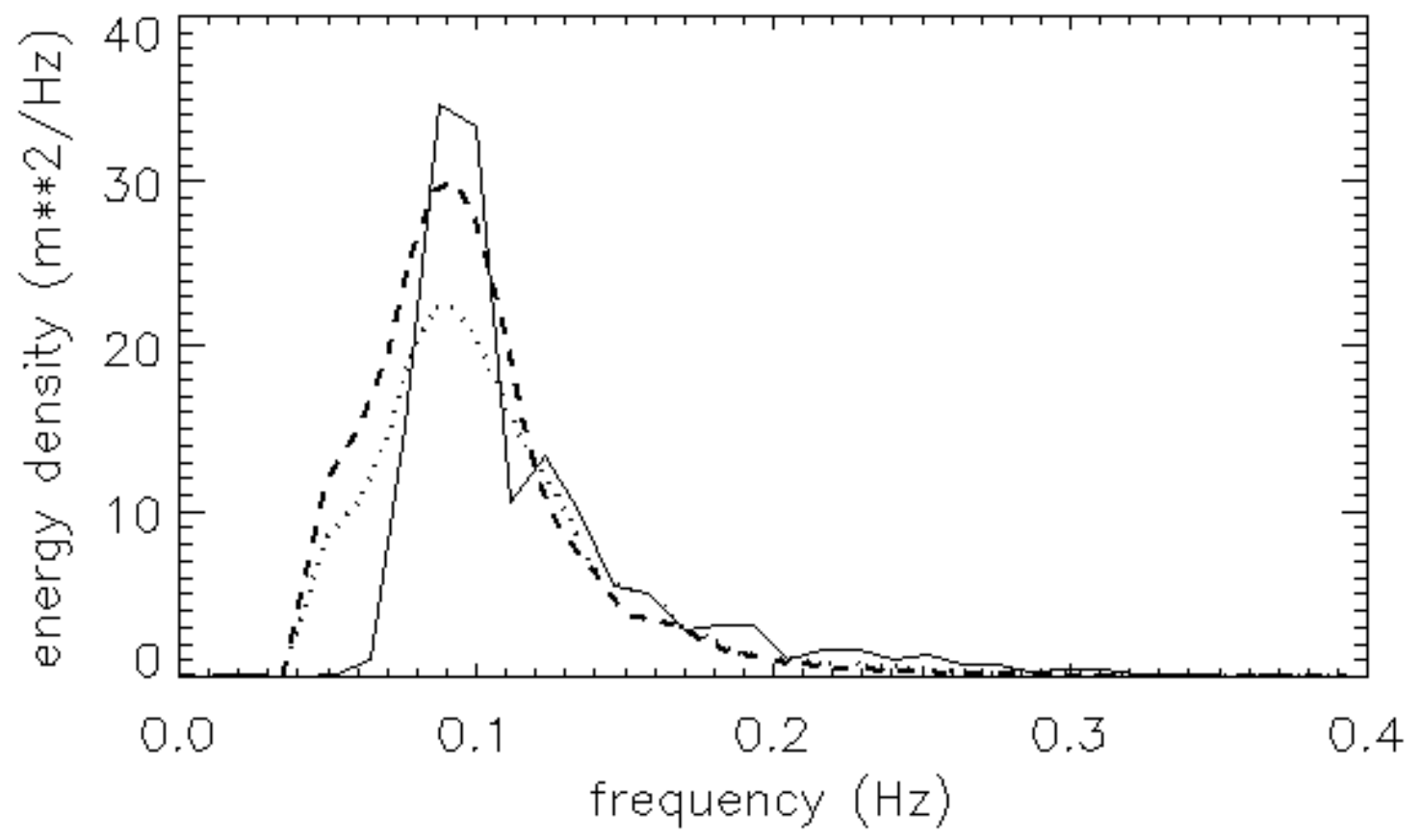

Figure 14. Omnidirectional sea wave frequency spectrum from the Lion buoy at 12:00 on 6 march 2013 (solid line). Omnidirectional frequency spectrum from KuROS just before overflight of the buoy (dotted line), and just after overflight (dashed line). 


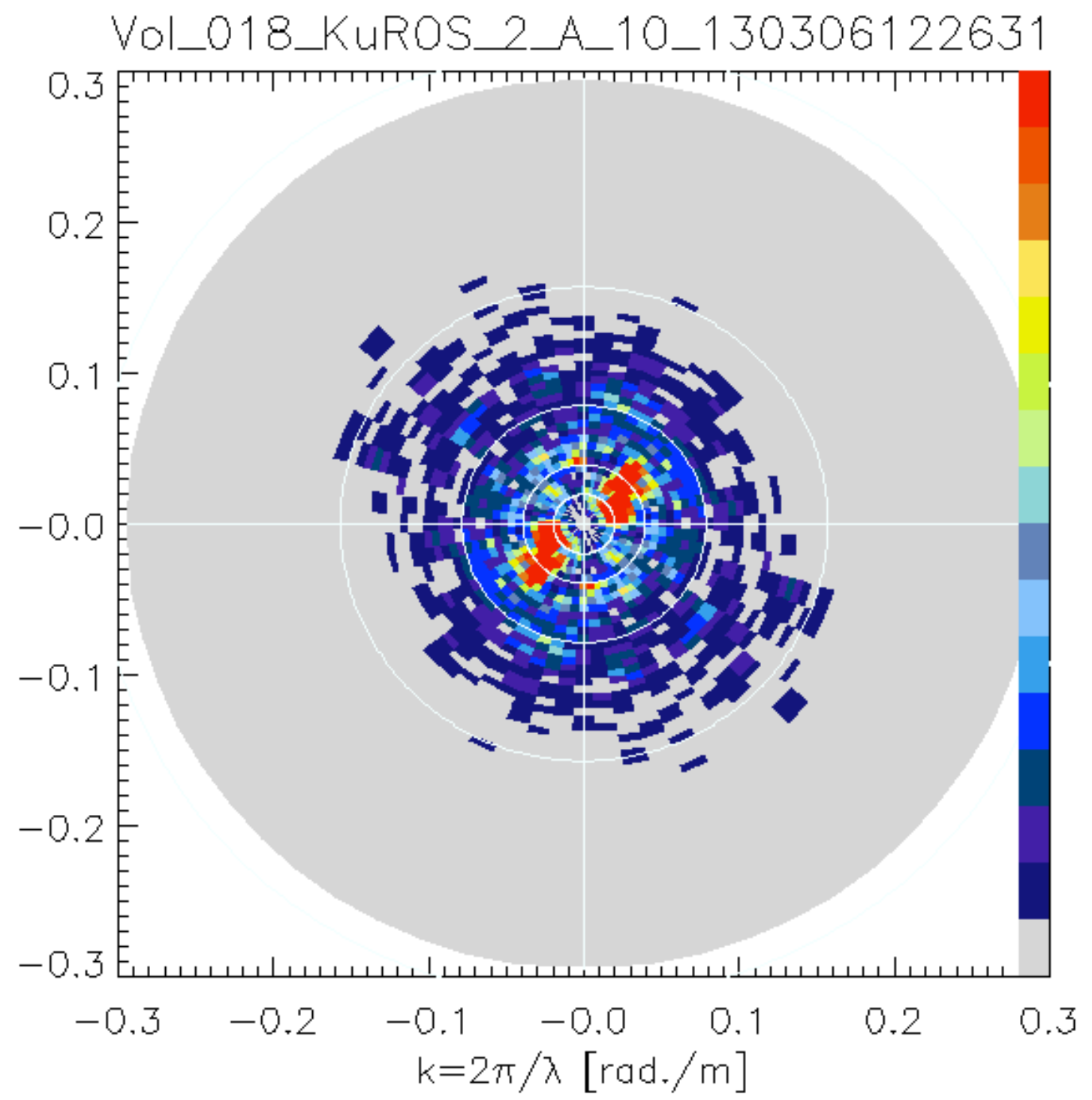

Figure 15. Directional sea wave slope spectrum $\mathrm{k}^{2} \mathrm{~F}(\mathrm{k}, \varphi)$ obtained from an altitude of $2000 \mathrm{~m}$. Radial direction is wavenumber and polar angle is azimuthal direction with North upward. The spectrum has been symmetrized because the measured modulation spectrum of $\sigma^{\circ}$ is proportional to the sea wave slope spectrum. The color code corresponds to 16 identical intervals, from 0 to the highest value. 
(a)

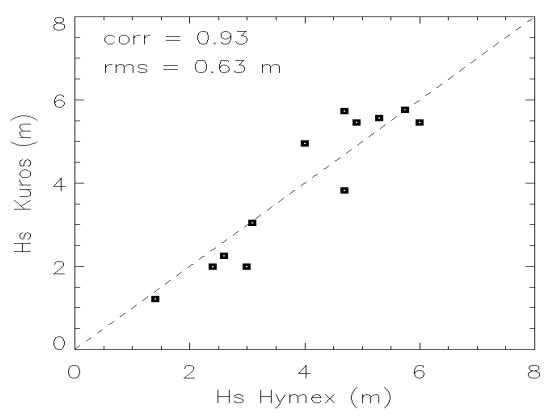

(b)

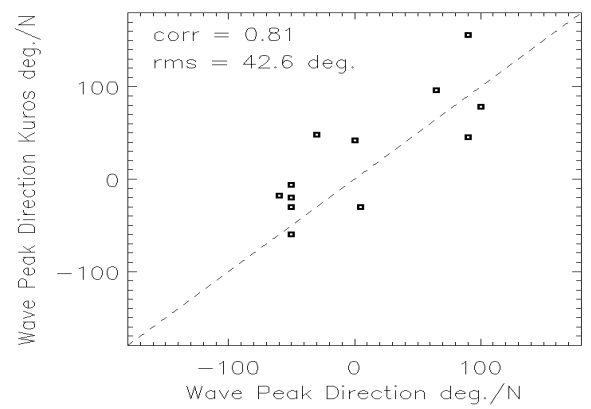

(c)

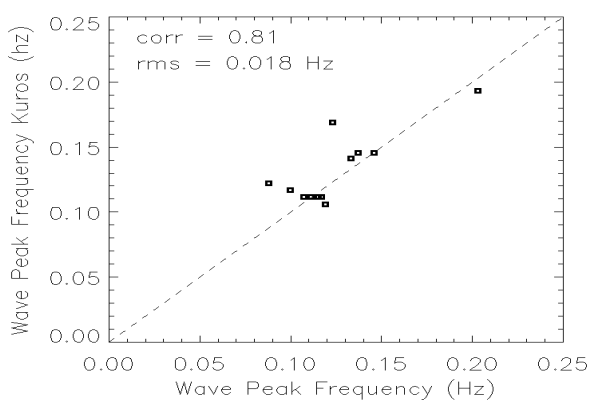

Figure 16. Comparison between the observations performed by the Lion buoy (abscissa) and KuROS (ordinate) at the times of the overflights. The flights are those of the HyMeX campaign as listed in Table 4. (a) significant wave height Hs ; (b) wave peak direction; (c) wave peak frequency. The correlation coefficient and rms difference between buoy and radar measurements are also indicated on the plots. 


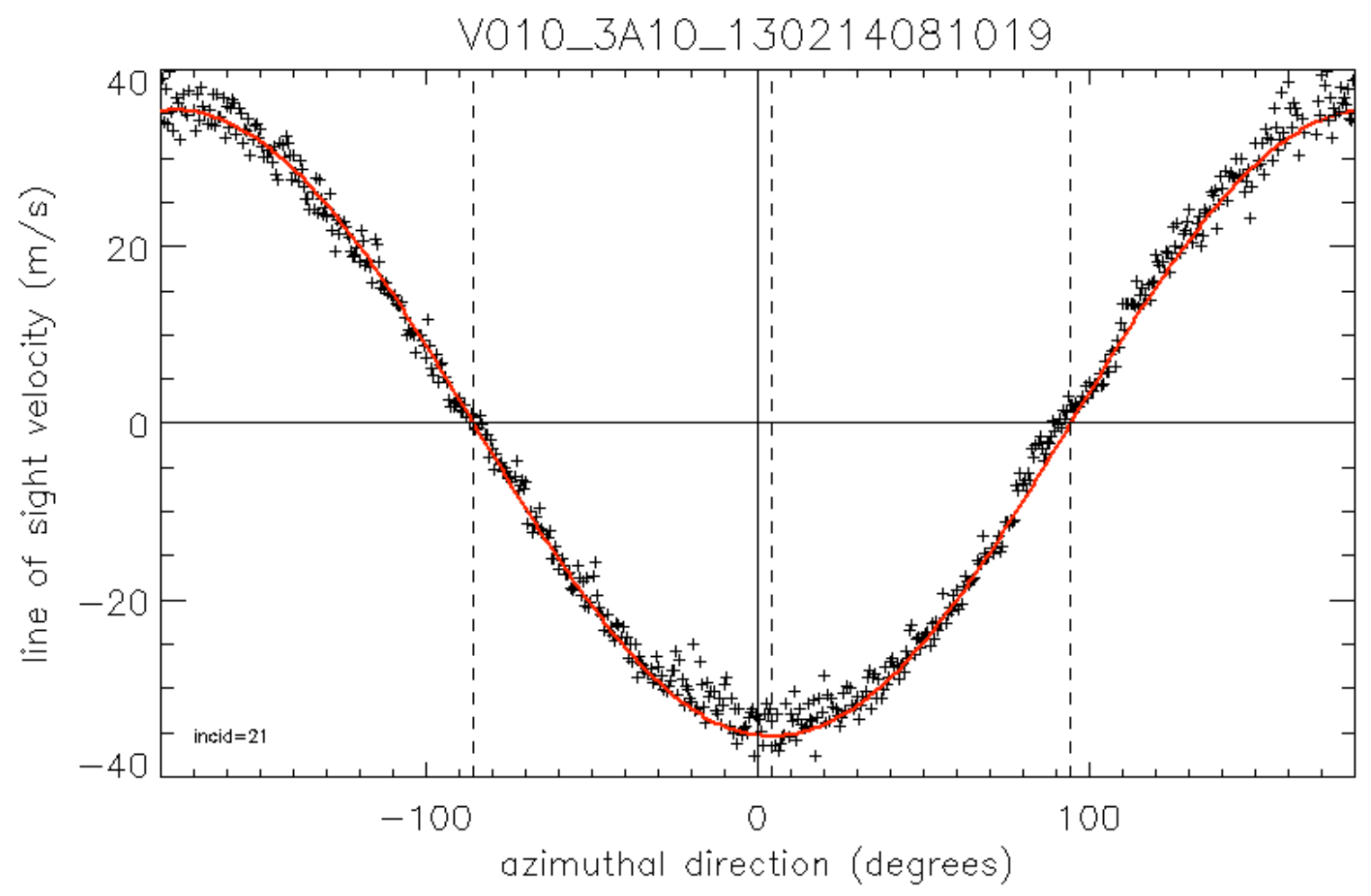

Figure 17. Doppler velocity as a function of azimuthal direction of the antenna beam relative to the airplane velocity (including correction of airplane drift angle due to crosswind), for an incidence angle of $21^{\circ}$, measured over the sea from $3000 \mathrm{~m}$ altitude $(+$ signs $)$. The vertical axis (solid line) is the direction along the aircraft velocity, while the vertical dashed lines are the directions along and perpendicular to the aircraft velocity, shifted by $4^{\circ}$ due to antenna offset. The red solid line is the theoretical velocity expected from a motionless flat soil (taking into account the $4^{\circ}$ antenna offset). The Doppler velocity is counted as positive for a displacement away from the radar. 


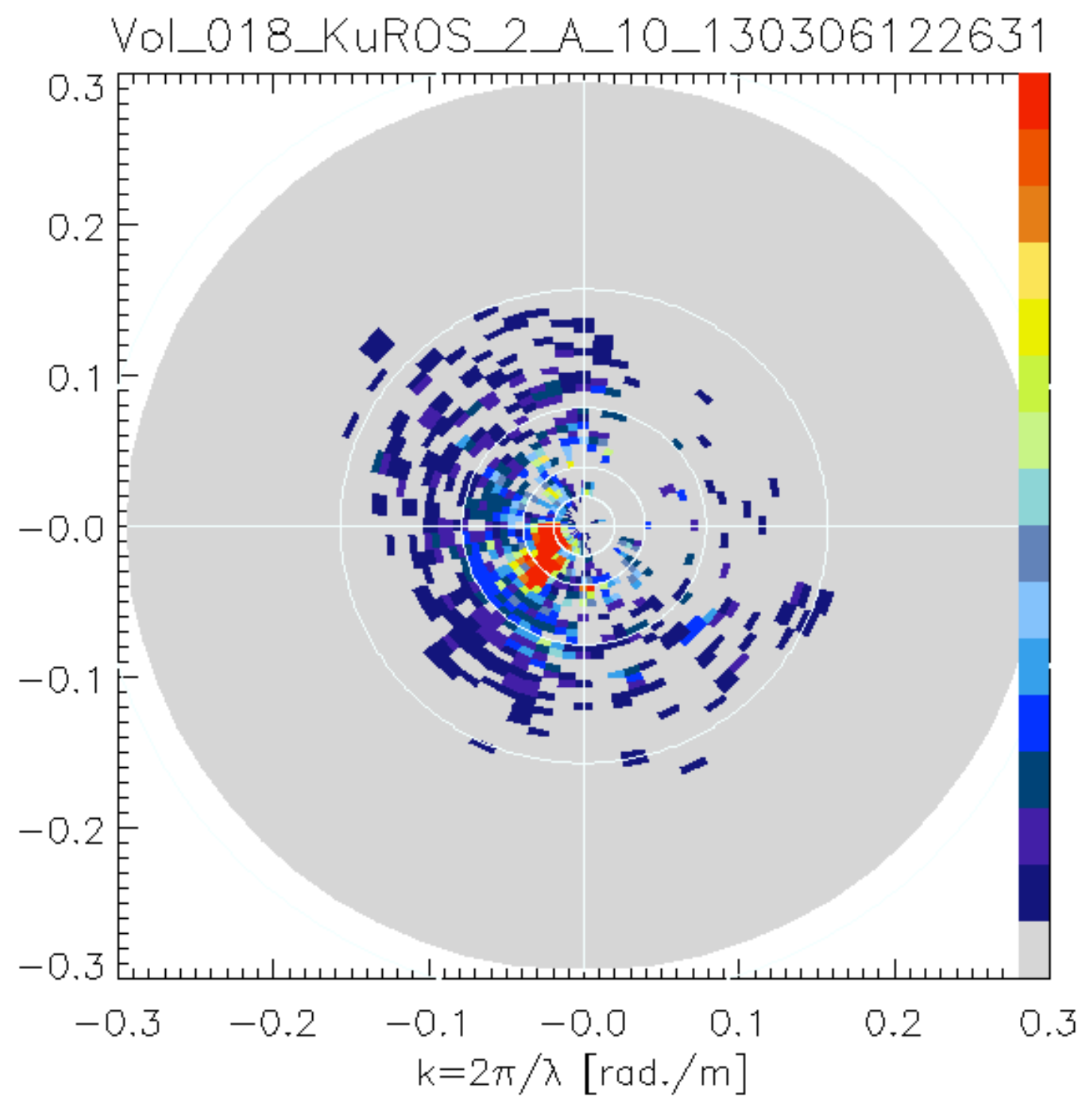

Figure 18. Same as Figure 15, but the $180^{\circ}$ ambiguity of the directional sea wave spectrum has been removed by combining the observations of $\sigma^{\circ}$ and velocity (see text). North is upward, and the azimuth angle indicated is the direction toward which the sea wave component is propagating. 


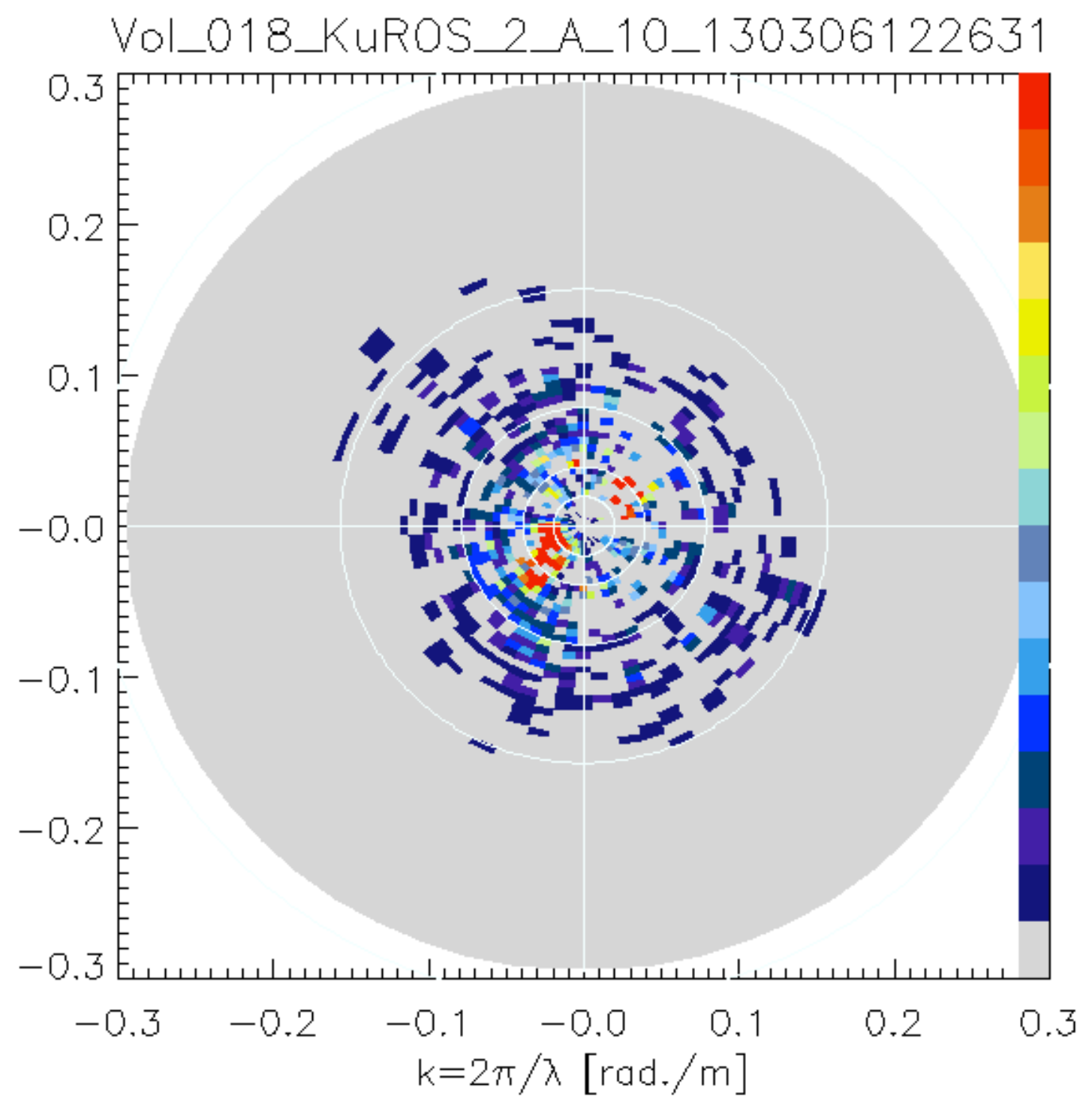

Figure 19. Same as Figure 18, but the ambiguity removal is obtained from the phase velocity of sea waves instead of orbital velocity of the surface. The time lag is taken as $\Delta \mathrm{T}=0.4 \mathrm{sec}$ 


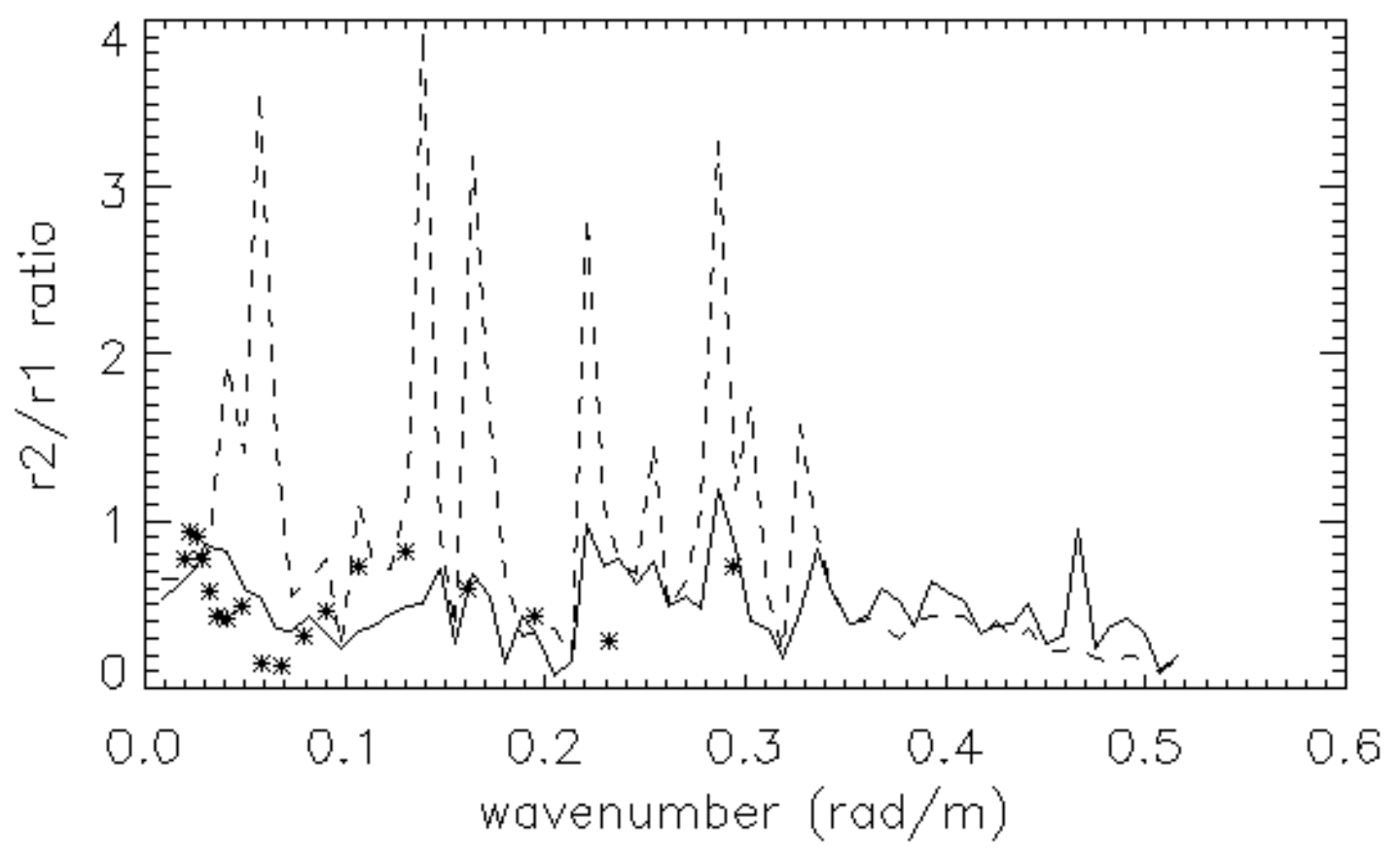

Figure 20. Ratio $\rho=r_{2} / r_{1}$ between second and first harmonics, as a function of wavenumber. Solid line: KuROS data disambiguated by the orbital velocity. Dashed line: KuROS data disambiguated by the phase velocity. Stars : buoy data. 